\title{
Selective Associations in the Observational Conditioning of Fear in Rhesus Monkeys
}

\author{
Michael Cook \\ University of Wisconsin-Madison
}

\author{
Susan Mineka \\ Northwestern University
}

\begin{abstract}
Three experiments explored the issue of selective associations in the observational conditioning of fear. Experiment 1 results indicated that observer thesus monkeys acquired a fear of snakes through watching videotapes of model monkeys behaving fearfully with snakes. In Experiment 2 , observers watched edited videotapes that showed models reacting either fearfully to toy snakes and nonfearfully to artificial flowers ( $\mathrm{SN}+/ \mathrm{FL}-)$ or vice versa $(\mathrm{FL}+/ \mathrm{SN}-)$. $\mathrm{SN}+/ \mathrm{FL}-$ observers acquired a fear of snakes but not of flowers; $F L+/ S N-$ observers did not acquire a fear of either stimulus. In Experiment 3, monkeys solved complex appetitive discriminative (PAN) problems at comparable rates regardless of whether the discriminative stimuli were the videotaped snake or the flower stimuli used in Experiment 2. Thus, monkeys appear to selectively associate snakes with fear.
\end{abstract}

In the past 25 years, much research has been directed toward the study of selective associations. Research in this area has often been placed in broader theoretical contexts such as preparedness, belongingness, or biological constraints on learning. (For recent reviews, see Domjan, 1983; Domjan \& Galef, 1983; Johnston \& Pietrewicz, 1985; LoLordo \& Droungas, 1989; Öhman, 1986; Öhman, Dimberg, \& Öst, 1985). However, because of the controversies generated by use of these frameworks, most contemporary research in this area has employed the more theoretically neutral term selective association. Selective associations represent instances of experience-independent association bias in which certain combinations of stimuli are readily associable, for example, conditioned stimulus (CS) $)_{1}$-unconditioned stimulus (US) and $\mathrm{CS}_{2}-\mathrm{US}_{2}$, whereas other combinations are not (e.g., $\mathrm{CS}_{1}$ $\mathrm{US}_{2}$ and $\mathrm{CS}_{2}-\mathbf{U} \boldsymbol{S}_{1}$ ). Further, such differences in associability cannot be explicable by reference to the separate properties of each stimulus (e.g., differences in CS salience), but must instead be due to the interaction between the specific stimuli

Experiments 2 and 3 of this article were submitted as part of a doctoral dissertation by Michael Cook to the University of Wisconsin-Madison.

This research was supported in part by National Science Foundation Grant BNS 85-07340 to Susan Mineka. We thank Charles Snowdon at the University of Wisconsin-Madison for suggesting to us the use of videotaped stimuli; J. Bruce Overmier at the University of Minnesota for his suggestion to use the PAN paradigm; Jeffrey Schultz and Clark Thompson from the Instructional Media Development Center at the University of Wisconsin-Madison for their technical assistance in the preparation of the videotaped material; Lola Lopes at the University of Wisconsin-Madison and Andrew Tomarken at the Vanderbilt University for assistance with statistical analyses; and Randy Busse, Sharon Knautz, Joe Herzog, Jill Wilker, Veronica Kibler, Kenton Price, and Jim Ekman for their assistance in running subjects.

Correspondence concerning this article should be addressed to Susan Mineka, Department of Psychology, Swift Hall, Northwestern University, Evanston, Illinois 60208. used. In more formal terms, for an association to be selective, the rate of growth of the CS-US association cannot be adequately described by separate CS and US rate parameters, but can be characterized only by a single rate parameter unique to the specific CS-US combination (see LoLordo, 1979a, 1979b; Rescorla \& Wagner, 1972).

An important subdomain of the literature on selective associations has dealt with their possible role in mediating the nonrandom distribution of fears and phobias in humans. Fears of certain animals (e.g., snakes, spiders, insects) and certain situations (e.g., heights) seem overrepresented in the clinical population relative to how often such objects are likely to have been associated with trauma (e.g., De Silva, Rachman, \& Seligman, 1977; Marks, 1987, chap. 9; McNally, 1987; Mineka, 1985; Öhman et al., 1985; Seligman, 1971). Thus, the greater propensity with which individuals acquire a fear of "fear-relevant" stimuli (e.g., snakes) is presumed to be a consequence of the fact that such stimuli are selectively associable with aversive outcomes. In keeping with the established definition of a selective association, it must also be demonstrable that the ease with which fear-relevant stimuli are associated with aversive outcomes cannot be attributed to the intrinsic properties of fear-relevant stimuli. That is, one would not expect to see superior conditioning when fearrelevant CSs were paired with nonaversive USs.

Much of the research involving Pavlovian conditioning to fear-relevant versus fear-irrelevant stimuli has been conducted by Öhman and his colleagues. A typical study uses nonphobic human subjects, mild shock as the US, and either fear-relevant CSs (e.g., slides of snakes or spiders) or fear-irrelevant CSs (e.g., slides of flowers or mushrooms). Conditioning is usually indexed by differential (CS+ vs. CS-) electrodermal activity. Numerous studies have demonstrated that, following acquisition, differential responding continues longer in extinction for fear-relevant as opposed to fear-irrelevant cues (e.g., E. Cook, Hodes, \& Lang, 1986; Öhman, Fredrikson, Hugdahl, \& Rimmö, 1976; see Öhman et al., 1985, for a review; however, see McNally, 1987, for a summary of results indicating no effect of fear relevance). 
By themselves, such results do not provide complete evidence that fear-relevant stimuli are selectively associable with aversive outcomes. For example, it remains possible that the superior resistance to extinction with fear-relevant CSs is attributable only to their greater salience. Studies attempting to assess this possibility have crossed the factors of US type (shock vs. a nonaversive US) and CS type (fear relevant vs. fear irrelevant). Given such a design, inference of a selective association requires (a) superior conditioning in the fearrelevant/shock group compared with the fear-irrelevant/ shock group, and (b) a nonzero level of responding for the fear-irrelevant/nonaversive US group that is at least as strong as that for the fear-relevant/nonaversive US group. (In the case of equivalent conditioning in the two nonaversive US groups, ceiling as well as floor factors should not be constraining performance; i.e., measurement sensitivity should not be an issue.) It should be noted that complete consensus does not exist for the second of these criteria; some investigators argue that a more stringent cross-over effect is necessary: greater conditioning in the fear-irrelevant/nonaversive US group than in the fear-relevant/nonaversive US group (e.g., LoLordo, 1979a, 1979b; McNally, 1987; cf. LoLordo \& Droungas, 1989, for recent arguments in support of the less stringent criterion). Unfortunately, the results of such studies (Öhman, Fredrikson, \& Hugdahl, 1978; Öhman et al., 1976) have fulfilled only the first of the two criteria; in the case of the second, both of the nonaversive US groups showed little if any conditioning. Such a pattern of results does not clearly invalidate explanations based on differences in CS properties because the nonaversive US may be incapable of supporting conditioning to any CS.

In addition, the relevance of studies by Öhman and others for understanding the nonrandom distribution of human fears and phobias is limited by several factors. First, selective associations supposedly represent experience-independent biases in stimulus associability; yet because humans are used as subjects, it may be impossible to equate the two stimulus classes (fear relevant vs. fear irrelevant) in terms of strength of prior associations (Delprato, 1980; Hygge \& Öhman, 1978). Second, the conditioned response (CR) in these studies, like most fear CRs conditioned in the laboratory where mild USs have been used, extinguish after a moderate number of trials, whereas phobic fear is notoriously resistant to extinction. Furthermore, these studies have generally only used autonomic measures of fear, thus leaving unanswered the question of whether fear-relevance effects can be demonstrated when other dependent measures are used (see Lang, 1968, 1971; Mineka, 1979, 1985; Rachman \& Hodgson, 1974).

An animal model of phobic behavior developed in recent years in our laboratory seemed to provide a promising avenue for overcoming some of the problems inherent in human research on this topic (see Mineka, 1985, for discussion of animal models of fears and phobias). Specifically, this model has been built on the fearful reactions to snakes exhibited by a wide variety of primate species reared in the wild, including white-faced capuchins (Cebus capucinus; Boinski, 1988); saddle-back tamarins (Saguinus fuscicollis nigrifrons; Bartecki \& Heymann, 1987); vervet monkeys (Cercopithecus aethiops; Seyfarth, Cheney, \& Marler, 1980a, 1980b; Struhsaker, 1967); and rhesus monkeys (Joslin, Fletcher, \& Emlen, 1964; Mineka, Keir, \& Price, 1980). These observations constitute presumptive evidence that snakes are a fear-relevant stimulus for primates.

Although considerable controversy has existed over the extent to which this fear of snakes is "innate" as opposed to based on learning, current evidence suggests that learning is necessary for the fear to manifest itself, at least for some primate species in which wild-reared but not laboratory-reared monkeys show a fear of snakes (see Mineka \& Cook, 1988, for a review). For example, Mineka and Cook demonstrated that laboratory-reared rhesus monkeys who were initially unafraid of snakes rapidly acquired a fear of snakes after watching wild-reared model monkeys exhibit a strong fear of snakes (Cook, Mineka, Wolkenstein, \& Laitsch, 1985; Mineka, Davidson, Cook, \& Keir, 1984). The naive laboratoryreared observers initially reached rapidly for food placed adjacent to a series of stimuli, including a real snake, toy snakes, and neutral objects. They were then allowed to watch a wild-reared model monkey react to these stimuli in the same setting: In the presence of snake stimuli, the models failed to reach for food and displayed a relatively large number of disturbance behaviors. In the presence of neutral stimuli, models readily reached for food and displayed no fear behaviors. Following this discriminative observational conditioning procedure, the observers were retested alone: A majority displayed an intense fear of snakes, indicated by increased latency to reach for food and increased distress. To examine the strength/persistence of the acquired fear, observers were retested 3 months later: There was no diminution in the intensity of the acquired fear on any of the measures.

The extension of this observational conditioning paradigm to the issue of selective associations requires two observer groups, one watching a model reacting fearfully to fear-relevant stimuli such as snakes (but nonfearfully to fear-irrelevant stimuli such as flowers), and the other watching a model reacting fearfully to fear-irrelevant stimuli (and nonfearfully to fear-relevant stimuli). Preliminary evidence of a selective association would be provided if observers in the first group acquired a fear of the fear-relevant snakes but not of the fearirrelevant flowers, and observers in the second group acquired significantly less (or no) fear of the fear-irrelevant flowers. However, to provide a valid comparison of the two observer groups, the procedure must be additionally modified to ensure that the models exhibit identical levels of fear in the presence of the to-be-feared stimulus (snake or flowers). This requirement stems from previous results from this laboratory indicating that the level of fear acquired by observers is positively correlated with the degree of model disturbance during the conditioning process (Cook et al., 1985; Mineka et al., 1984).

A technological avenue toward creating models displaying equivalent behavior but to different stimuli would involve the observer watching not an actual model but a videotaped model. Specifically, by splicing in the appropriate stimulus objects (snakes or flowers), one could ensure identical model behavior in the presence of different stimuli. Thus, in videotapes seen by some observers the model would appear to react fearfully to the snake and nonfearfully to the flowers, whereas in videotapes seen by other observers the same model (dis- 
playing the identical behavior) would appear to react nonfearfully to the snake and fearfully to the flowers (see Mineka, 1987; Mineka \& Cook, 1988, for preliminary discussions of this issue).

Before proceeding with such a design, it was first necessary to determine whether monkeys could acquire a fear of snakes through observation of videotaped models. Past research involving the presentation of color videotapes to various macaque species indicated that subjects respond to videotaped conspecifics in a socially appropriate manner (Capitanio, Boccia, \& Colaiannia, 1985; Lande, Higley, Snowdon, Goy, \& Suomi, 1985; Plimpton, Swartz, \& Rosenblum, 1981). It remained unclear, however, whether monkeys could acquire a fear of a CS by watching videotaped conspecifics. Therefore, Experiment 1 sought to determine whether observers could acquire significant levels of snake fear by watching videotaped rather than live models. ${ }^{1}$ Experiments 2 and 3 build on the findings of Experiment 1, attempting to demonstrate that the conditioning of snake fear represents a selective association.

\section{Experiment 1}

\section{Method}

\section{Observers and Models}

Observers were 6 (4 males and 2 females) laboratory-reared rhesus monkeys (Macaca mulatta) ranging in age from 5 to 9 years. The videotaped models were a 31-year-old female wild-reared rhesus monkey and a 6-year-old female laboratory-reared rhesus monkey. The wild-born model had had approximately 5 years of experience in the wild in India before capture. The laboratory-reared model had acquired a fear of snakes through observation in a previous experiment (Mineka \& Cook, 1986). All monkeys were living at the Harlow Primate Laboratory at the time of the experiment.

\section{Apparatus}

Testing took place in a Wisconsin General Test Apparatus (WGTA; Harlow, 1949) and a Sackett Self-Selection Circus (hereafter referred to as Circus; Sackett, 1970). In the WGTA, the experimenter sat behind a one-way mirror, unobserved by a monkey in a cage $(98.5$ $\mathrm{cm}$ long $\times 52.6 \mathrm{~cm}$ high $\times 51.4 \mathrm{~cm}$ wide). During WGTA adaptation and testing, stimuli were placed inside an uncovered Plexiglas box $(53.4 \mathrm{~cm}$ long $\times 15.2 \mathrm{~cm}$ high $\times 21.3 \mathrm{~cm}$ wide) and food reinforcers were placed on a ledge at the top of the back wall of the box (the wall farthest from the monkey). A blind, when lowered by the experimenter, prevented the monkey from viewing the box, stimulus, and reinforcer. During observational conditioning, a color monitor (NEC, Model CM-1915A, 19-in [48.3-cm] screen) connected to a videocassette recorder (VCR; Sony, Model SL-10) was situated within the WGTA (approximately $1 \mathrm{~m}$ from the cage holding the monkey) so that the monkey could view the videotaped stimuli on the monitor's screen when the blind was raised. Low-level white noise masked any extraneous noise occurring during WGTA sessions.

The Circus consisted of a hexagonal center compartment surrounded by six rhomboidal-shaped outer compartments. The center compartment communicated with each outer compartment via guillotine-type doors that were pneumatically raised and lowered. The outer compartments were separated from each other by opaque walls.
Four of the six outer compartments were used as stimulus compartments; stimulus compartments had a guillotine door and an outer wall (i.e., the wall opposite the center compartment and the guillotine door) constructed of Plexiglas. Stimulus objects were placed inside cages $(53 \mathrm{~cm}$ long $\times 35 \mathrm{~cm}$ high $\times 30 \mathrm{~cm}$ wide) with one side $(53 \mathrm{~cm}$ $\times 35 \mathrm{~cm}$ ) made of Plexiglas. Fach cage was placed with its Plexiglas side facing the outer Plexiglas wall of a stimulus compartment, so that a monkey inside that compartment could view the stimulus. One of the six outer compartments was used as a start compartment. Its guillotine door and outer wall were opaque to prevent monkeys from looking into or out of that compartment. The sixth compartment was not used in this experiment; its guillotine door remained lowered and was opaque to prevent visual access. A videocamera (Panasonic, Model WV-200), placed above the apparatus and connected to a black and white monitor (Setchell Carlson, Model 9M912, 19-in [48.3 $\mathrm{cm}$ ] screen) in an adjacent room, allowed the experimenter to view the monkey within the Circus. Low-level white noise masked any extraneous noise occurring during Circus sessions.

\section{Stimuli}

The following stimuli were presented to observers in the WGTA or in the Circus, or both: (a) a live boa constrictor (Constrictor constrictor), approximately $132 \mathrm{~cm}$ long and $4.5 \mathrm{~cm}$ in diameter (hereinafter referred to as the real snake); (b) a 157-cm-long, sinuous, brown and white, inflatable toy snake (the huge toy), $7.6 \mathrm{~cm}$ in diameter; (c) a 106-cm-long, sinuous, brown, rubber toy snake, 2.5 $\mathrm{cm}$ in diameter (the big toy); (d) a 61-cm-long, sinuous, brown, rubber toy snake, $2.5 \mathrm{~cm}$ in diameter (the small toy); and (e) several "neutral" objects: wood blocks of different shapes and colors, the largest measuring $2.5 \mathrm{~cm}$ high $\times 7.6 \mathrm{~cm}$ long $\times 7.6 \mathrm{~cm}$ wide.

\section{Videotapes}

Two videotapes were used. One tape showed the wild-born model; the other showed the laboratory-born model. In each tape, the model reacted fearfully to the real snake and to the huge toy snake and nonfearfully to neutral stimuli. Fear (or lack of fear) was manifested by the models reacting to the stimuli and food treats in a WGTA setting. Neutral stimuli were inside the uncovered Plexiglas box; the real and huge toy snakes were only partially inside the box. Both the real snake and huge toy were moving for most of the time they appeared on the tapes. Movement of the toy was induced by the experimenter; the experimenter did not, however, appear on the videotape. In the case of all three stimuli, food reinforcers could be seen on the ledge of the box. During those trials on which a neutral stimulus appeared in the open box, the models reached rapidly (within $5 \mathrm{~s}$ ) over the object to obtain the food, indicating no fear of the neutral objects. During those trials on which the real snake or huge toy appeared in the box, the model evinced extreme fear for $60 \mathrm{~s}$, manifested by a failure to reach over the moving snake for the food and by the display of various fear behaviors; see Procedure for an enumeration of fear behaviors.

Each tape was comprised of 30 trials, 24 neutral-object trials (each approximately $5 \mathrm{~s}$ in duration), and six 60-s snake trials, 3 with the

\footnotetext{
'A brief version of these results was presented in Mineka (1987). Because of a difference in the way Wisconsin General Test Apparatus (WGTA) responses were averaged, the graphed WGTA results in Mineka (1987) appear to indicate mean responses that are twice those shown in the present report. However, this discrepancy represents a difference in scale, not in actual response magnitude.
} 
real snake and 3 with the huge toy snake. For each tape, trial order was as follows: 12 neutral-object trials, 6 snake trials, and 12 neutralobject trials. Intertrial intervals (ITIs) varied from approximately 5 to $20 \mathrm{~s}$. The duration of the tape showing the wild-born model was approximately $12.5 \mathrm{~min}$; the duration of the tape showing the laboratory-born model was approximately $13 \mathrm{~min}$.

The images of the snake stimuli, as they appeared on the videotapes, varied considerably between and within trials, because they were frequently moving and because the focus of the videocamera changed occasionally during taping. Further, neither the real snake nor the huge toy snake appeared in their entirety on the screen (although typically their heads were visible). In general, the diameter of the image of the real snake was approximately $3.8 \mathrm{~cm}$ and that of the huge toy was approximately $5.1 \mathrm{~cm}$. Similarly, the image of the model monkeys varied considerably; in general, the height of the image was approximately $20 \mathrm{~cm}$. The screen image of the neutral blocks was approximately $3.2 \mathrm{~cm}$ wide, and that of the food treat was approximately $1 \mathrm{~cm}$ in diameter.

\section{Procedure}

WGTA adaptation and pretest. Observers were adapted to the WGTA apparatus and procedure before the WGTA pretest. An adaptation trial consisted of placing a neutral object inside the Plexiglas box, placing a food treat on the box's ledge, raising the blind (allowing the mankey to see the box, stimulus, and reward), and starting a timer. The trial ended when the monkey reached over the neutral object in the open box to obtain the food. ITIs varied from approximately 5 to $15 \mathrm{~s}$. Monkeys were considered adapted when they obtained the food within $10 \mathrm{~s}$ on 18 of 20 consecutive trials.

Following adaptation, observers were pretested in the WGTA for their fear of the real snake and toy snakes. The pretest procedure differed from the adaptation procedure in the following particulars:

1. Trials did not end when the observer obtained the food, but were all $60 \mathrm{~s}$ long. If the observer failed to obtain the food during a trial, a latency of $60 \mathrm{~s}$ was recorded.

2. The occurrence of any of 12 disturbance behaviors was recorded. Disturbance behaviors were scored using a 1-0 modified frequency system (Sackett, 1978). A 60-s trial was subdivided into three 20-s intervals. If a particular disturbance behavior occurred one or more times during a 20-s interval, the observer's disturbance score was increased by 1 . Because there were 3 intervals per trial, each of the 12 behaviors could increment the composite disturbance score by 0 to 3 . The disturbance behaviors recorded were those used previously with this paradigm (Cook \& Mineka, 1987; Cook et al., 1985; Mineka \& Cook, 1986; Mineka et al., 1984; Mineka et al., 1980): fear withdrawal (sudden retreat to or flattening of the body against the back of the cage, or both), cage clutch (holding onto the side or the back of the cage), cage shake (vigorous moving or shaking of the cage), spasm or tic (vigorous shaking or jerking of the hands or upper body), eye aversion (rapidly looking away from the stimulus), stare (prolonged, fixed gaze at the stimulus from the back of the cage), fear grimace (stretching the lips over the gums, exposing the teeth), threat (lips thrust forward, ears retracted or flattened against the head), ear flap (ears flattened against the head but without the lips thrust forward as with a threat), lip smack (lips repeatedly moving up and down, chattering of teeth), vocalization, and piloerection (fur raised up on the shoulders and torso).

3. Five stimuli were presented in the Plexiglas box: the real snake, the huge, big, and small toy snakes, and the neutral blocks. (Because of its size, only a portion of the huge toy was inside the box. Subjects could still reach over the huge toy for the food treat, however.) Presentation order of stimuli was as follows: Two neutral-object trials preceded the presentation of the four snake stimuli. The snake trials were separated from one another by a further neutral-object presentation. This sequence of 9 trials was then repeated, resulting in a total of 18 trials; thus, each snake stimulus was presented twice. ITIs were approximately $45 \mathrm{~s}$ long.

Circus adaptation and pretest. During a Circus session, an observer was confined to the start compartment for a 5 -min period, after which the guillotine doors separating the center compartment from the start and stimulus compartments were opened. When the observer exited from the start compartment (usually within $10 \mathrm{~s}$ ), the door of that compartment was lowered to prevent reentry. The observer could then enter and leave any of the stimulus compartments and the center compartment during the next $5 \mathrm{~min}$. The amount of time spent inside each of the stimulus compartments was recorded.

Observers received adaptation sessions to familiarize them with the apparatus and procedure and to ensure that they displayed no compartment preferences. Four neutral objects were used as stimuli. Sessions continued for each observer until a criterion of four consecutive sessions of "no preference" was met: spending $5 \%$ to $40 \%$ of the total entry time in each stimulus compartment. Observers then received a Circus pretest. The pretest procedure differed from the adaptation procedure only in the four stimuli used: The real snake, the big and small toy snakes, and one neutral object were presented. (The huge toy snake was too large to be presented in this apparatus.) WGTA and Circus adaptation occurred over a 3 to 6 week period. Pretests were conducted after adaptation criteria had been met in both contexts.

Observational conditioning. Following the WGTA and Circus pretests, observers underwent six observational conditioning sessions over 2 to 3 weeks. During each session, observers were allowed to watch the two videotapes in the WGTA setting. It was not necessary to train observers to watch the videotapes. Because the monitor was situated so that it obscured the ability of the experimenter to view the observers, systematic observations of the monkeys' behavior during conditioning was not possible. A one-way mirror in the door of the experimental room was occasionally used by the experimenter, who was situated outside the room, to make incidental observations of observer behavior during conditioning. However, the view provided by this one-way mirror was not adequate to allow systematic, reliable observations of behavior.

Circus and WGTA posttests and follow-up. Following the second observational conditioning session, observers were given a posttest in the Circus. This posttest was procedurally identical to the Circus pretest. This cycle of 2 observational conditioning sessions followed by a Circus posttest was repeated 2 more times so that observers received a total of 6 conditioning sessions and 3 Circus posttests. Following the final Circus posttest, observers received a WGTA posttest identical in procedure to the WGTA pretest. Approximately 3 months after the WGTA posttest, observers received follow-up tests in the Circus and the WGTA. The follow-up test procedures were identical to the posttest procedures.

\section{Data Analysis}

Three investigators scored fear behaviors over the course of the experiment. Interrater agreement was assessed during 4 WGTA posttests. During each of the assessment sessions, 2 of the 3 aforementioned investigators were present. The first author was always 1 of the 2 (and had trained the other 2 investigators). Interrater agreement was $88 \%$; that is, 65 of the 74 behaviors recorded over the 72 trials were noted by both raters. If the instances for which the raters agreed no fear behaviors occurred were included in the assessment, agreement would exceed $99 \%$.

For WGTA pretest, posttest, and follow-up sessions, the maximum attainable latency score per trial was $60 \mathrm{~s}$; the maximum attainable 
disturbance behavior score per trial was 36 (three 20 -s intervals $\times 12$ behaviors). ${ }^{2}$ For each WGTA session, a single food-reach latency (and disturbance behavior) score was computed for each type of snake stimulus by averaging scores over the 2 trials during which the stimulus was presented. Latency and fear behavior scores for the neutral stimuli were derived by averaging scores for the first 2 neutralobject trials of a session. For the Circus sessions, amount of time spent in each stimulus compartment (compartment time) was the dependent measure. The maximum possible compartment time score was $300 \mathrm{~s}$.

For each of the 3 dependent measures, experimental hypotheses were tested with 3 sets of planned comparisons; each set was related to a logically distinct experimental hypothesis. The first set sought to confirm the expectation that responding during the pretest did not differ for the different stimuli; the second set tested hypotheses concerning demonstration of the acquisition of snake fear at posttest; and the third examined whether acquired fear was maintained at follow-up. For the WGTA dependent measures, these 3 sets took the following form:

In Set 1, (a) $R_{\text {pretest }}-\mathrm{N}_{\text {pretes, }}$ and (b) BS pretest $-\mathrm{N}_{\text {pretest, where }} \mathrm{RH}$ represents the mean of the responses to the real snake and the huge toy snake at the specified experimental phase, BS is the mean of the responses to the big toy and small toy snake, and $\mathrm{N}$ is the response to the neutral object. The snake stimuli were averaged in this way because the real snake and huge toy snake differed from the big and small toy snakes in 2 important respects. First, the former stimuli were considerably larger than the latter. Second, the former stimuli, unlike the latter, were presented to observers on videotape during observational conditioning. In Set 2 , (a) $\left(\mathrm{RH}_{\text {postrest }}-\mathrm{N}_{\text {pustest }}\right)-$ $\left(R_{\text {pretest }}-N_{\text {pretes }}\right)$, and (b) $\left(B S_{\text {posttest }}-N_{\text {postess }}\right)-\left(B S_{\text {pretest }}-N_{\text {pretest }}\right)$. In Set 3, (1) $\mathrm{RH}_{\text {follow-up }}-\mathrm{RH}_{\text {postest, }}$ and (b) $\mathrm{BS}_{\text {follow-up }}-\mathrm{BS}_{\text {postlest. }}$ The 3 analogous sets used for Circus compartment time differed from those used for the WGTA measures only in that they examined responses to the real snake, $R$, rather than to the $R H$ aggregate (because the huge toy snake was not presented in the Circus).

An effort was made to control experimentwise Type I error by adopting a Dunn-Bonferroni strategy for setting the nominal alpha level at which the contrasts were evaluated (Dunn, 1961). Thus, each comparison in the 3 sets was evaluated at $\alpha=.05 / 2=.025$. As a result, experimentwise alpha associated with each dependent measure was equivalent to what would have been yielded had we conducted 3 planned comparisons, each evaluated at $\alpha=.05$. All planned comparisons were two-tailed.

Omnibus analyses of variance (ANOVAs) for each dependent measure were also conducted. Departures from sphericity can strongly bias the results of repeated-measures ANOVAs as well as the results of planned comparisons involving repeated measures (Rogan, Keselman, \& Mendoza, 1979; Vasey \& Thayer, 1987). For this reason, where sphericity assumptions are violated, $F$ values are reported with the conservative degrees of freedom recommended by Greenhouse and Geisser (1959). Additionally, the planned comparisons were calculated using separate comparison-specific error terms (Boik, 1981; Maxwell, 1980).

\section{Results}

In overview, the results revealed strong and persistent observational conditioning of snake fear in the observers. Two of the 3 dependent measures indicated that, whereas observers showed little or no fear of the snake stimuli at pretest, follow. ing exposure to the videotapes they exhibited a fear of some or all of the snake stimuli (depending upon the dependent measure).

\section{Observational Conditioning}

Incidental observations suggested that the observers reacted to the videotaped stimuli as if they were real. For example, observers occasionally reached for the food treat appearing on the screen. In addition, observers sometimes exhibited signs of behavioral disturbance coincident with the model's fear performance, just as we have typically seen when using live models (e.g., Cook et al., 1985). In general, levels of observer disturbance were higher during early conditioning sessions than during later conditioning sessions.

\section{Circus}

A $3 \times 4$ (Tests [pretest, average posttest, follow-up] $\times$ Stimulus Objects [real snake, big and small toys, neutral object]) repeated measures ANOVA compared observer behavior in the Circus at the pretest, average posttest, and followup. A significant main effect for objects, $F(1,5)=10.95$, and a significant Tests $\times$ Objects interaction, $F(1,5)=4.14$, were revealed. Posttest values were averaged across the 3 individual posttest sessions in the foregoing analysis because a preliminary $3 \times 4$ (Circus Posttest Sessions $\times$ Stimulus Objects) repeated measures ANOVA of observer performance during the individual posttests revealed that neither the main effect for posttest sessions nor the Sessions $\times$ Objects interaction were significant. That is, observer behavior did not significantly change over the individual posttests.

Planned comparisons indicated that observers spent an equivalent amount of time in all the stimulus compartments during the pretest. Unfortunately, despite the significance of the Tests $\times$ Objects interaction, the planned comparisons examining snake fear acquisition were only marginally significant $(p s=.067$ and .051 for the real snake and big toy/small toy, respectively). Figure 1 illustrates these results.

\section{WGTA}

Observer latency scores during the pretest, posttest, and follow-up were analyzed by a $3 \times 5$ (Tests [pretest, posttest, follow-up] $\times$ Stimulus Objects [real snake, huge, big, and small toy, neutral object]) repeated measures ANOVA, which revealed significant main effects for tests, $F(2,10)=15.86$, and objects, $F(4,20)=18.47$, as well as a Tests $\times$ Objects interaction, $F(1,5)=4.69$. Planned comparisons indicated that before observational conditioning observers responded to all stimuli with short, equivalent latencies. Following con-

\footnotetext{
${ }^{2}$ Although a disturbance score of 36 was theoretically obtainable, as in our previous experiments with live models (e.g., Cook et al., 1985 ), actual scores were far below this maximum for a variety of reasons. The expression of some behaviors were not compatible with the simultaneous expression of others (e.g., eye aversion vs. prolonged stare) so that the appearance of one such behavior during a $20-\mathrm{s}$ interval reduced the probability of the appearance of the conflicting behavior. Further, animals exhibiting fear tended to display only a subset of the 12 possible fear behaviors, with different monkeys displaying different subsets. Finally, some of the 12 fear behaviors appeared very infrequently.
} 


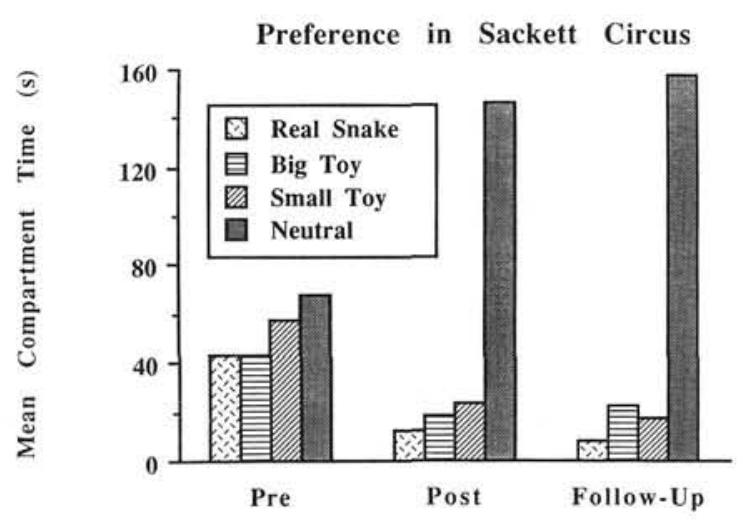

Figure 1. Mean compartment times in the Circus for four stimulus objects (real snake, big and small toy snakes, and neutral object) for the Experiment 1 observers at pretest, posttest, and follow-up.

ditioning, however, latencies in the presence of both types of snake stimuli increased significantly, whereas responding to neutral stimuli remained the same. This acquired fear was maintained at follow-up. Figure 2 depicts these results.

A $3 \times 5$ (Tests $\times$ Stimulus Objects) repeated measures ANOVA for observer disturbance behavior (analogous to the ANOVA for latency) showed significant main effects for tests, $F(2,10)=11.28$, and objects, $F(4,20)=18.60$, and a Tests $\times$ Objects interaction, $F(1,5)=4.44$. Planned comparisons indicated that before observational conditioning observers showed comparably few disturbance behaviors to all stimuli. Following exposure to the videotapes, disturbance scores reflected an acquired fear of the real snake and huge toy snake, but not of the big and small toy snakes. Fear of the real snake and huge toy was maintained at follow-up. Figure 3 depicts these results.

\section{Discussion}

The results of Experiment 1 demonstrate that naive, laboratory-reared monkeys can acquire a strong and persistent fear of snakes and snake-like stimuli by watching videotapes

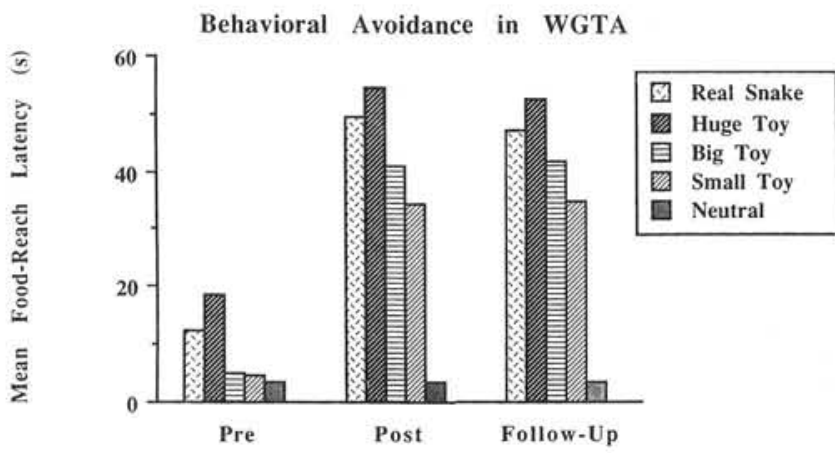

Figure 2. Mean food-reach latency in the Wisconsin General Test Apparatus (WGTA) in the presence of five stimulus objects (real snake; huge, big, and small toy snakes; and neutral object) for the Experiment 1 observers at pretest, posttest, and follow-up. of conspecifics reacting fearfully to these stimuli. Two of the 3 dependent measures indicated an acquired fear of the real snake and huge toy snake, that is, the snake stimuli viewed on the videotapes during conditioning. One of the measures showed that this fear generalized to other snake-like stimuli, the big and small toy snakes. The persistence of this fear was evident by its retention with little or no diminution three months following conditioning.

The failure of some of the planned contrasts to achieve statistical significance (viz., those for Circus compartment time), given that such contrasts had indicated acquired snake fear in previous studies using live models, can probably be attributed to the small sample size $(n=6)$ used in this preliminary study. Indeed, results from this study using videotaped models are substantially similar to those using a live-model procedure (although it should be noted that observers in this experiment spent 72 min watching videotaped models reacting to snakes as opposed to only $24 \mathrm{~min}$ in experiments with live models). For example, the mean posttest latency to the real snake in the present study is $49.5 \mathrm{~s}$ in contrast to $54.5 \mathrm{~s}$ for a live-model study (Mineka et al., 1984). In addition, mean compartment time for the real snake is $12.9 \mathrm{~s}$ in this study as opposed to $15.6 \mathrm{~s}$ for the same livemodel study.

The present results are of importance and interest for several reasons. First, they provide what we believe is the first empirical documentation that a primate species can not only recognize and react in a socially appropriate manner to videotapes of conspecifics, but also use such stimuli as a basis for emotional learning. To the extent that parallel effects occur in humans, these results suggest that the mass media may provide a potent source of information for the acquisition of fears and phobias (see Venn \& Short, 1973; cf. Bandura, in press, for related evidence on learning aggressive behaviors through the mass media). Additionally, these results allowed us to proceed with a further study that explored the issue of selective associations by comparing the effects of pairing fearful model behavior with fear-relevant stimuli (snakes) versus fear-irrelevant stimuli (flowers).

\section{Experiment 2}

In Experiment 2, one group of observers ( $\mathrm{SN}+/ \mathrm{FL}-$ ) watched edited videotapes in which models appeared to react fearfully to toy snakes and nonfearfully to flowers, whereas a second group $(\mathrm{FL}+/ \mathrm{SN}-)$ watched edited videotapes in which models appeared to react fearfully to the flowers and nonfearfully to toy snakes. Provisional evidence of a selective association would be provided if $\mathrm{SN}+/ \mathrm{FL}-$ observers acquired a fear of snakes but not of flowers. In contrast, $\mathrm{FL}+/ \mathrm{SN}-$ observers should not acquire a fear of snakes; fear of flowersif any-should be less than the snake fear of the $\mathrm{SN}+/ \mathrm{FL}-$ observers.

Several features of this design are noteworthy. First, because a discriminative observational conditioning paradigm was used, in which the CS+ is fear relevant and the CS- is fear irrelevant for one group, whereas the opposite arrangement is used for the other group, we could assess the possibility that any enhanced conditioning with the fear-relevant stimulus 


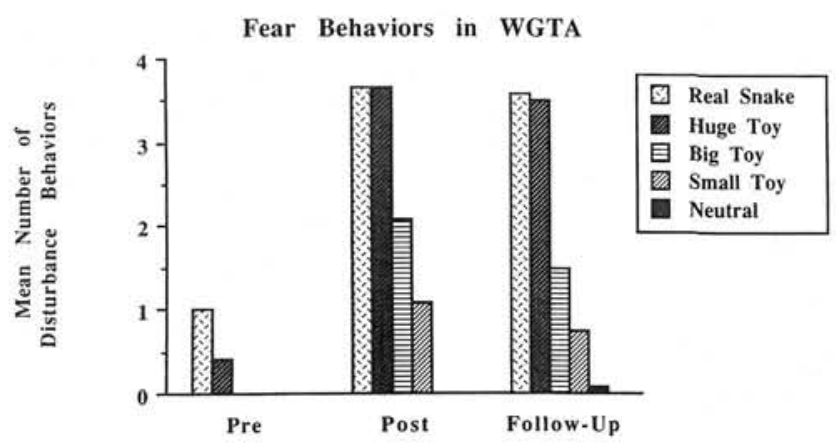

Figure 3. Mean number of disturbance behaviors exhibited in the Wisconsin General Test Apparatus (WGTA) in the presence of five stimulus objects (real snake; huge, big, and small toy snakes; and neutral object) for the Experiment 1 observers at pretest, posttest, and follow-up.

when it is a CS+ is due to selective sensitization rather than to purely associative processes. If selective sensitization is, in fact, responsible for any snake fear in the SN+/FL- observers, then we should see comparable fear of snakes in the FL+/ $\mathrm{SN}-$ observers, where snake stimuli are explicitly unpaired with the US (LoLordo, 1979a). Second, because the laboratory-reared observers had no experience with either snakes or flowers before the experiment, differential responding to the snake stimuli could not easily be ascribed to experiential factors occurring before the experiment as is the case with human research on this topic.

\section{Method}

\section{Observers and Models}

Observers were 26 ( 7 males and 19 females) laboratory-reared rhesus monkeys ranging in age from 4 to 22 years. ${ }^{3}$ The videotaped models were the same ones used in Experiment 1. All monkeys were living at the Harlow Primate Laboratory at the time of the experiment.

\section{Apparatus and Stimuli}

Testing took place in the WGTA and Circus used in Experiment 1. The following stimuli were presented to observers in the WGTA or in the Circus, or both: (a) the real snake; (b) the big toy snake; (c) the small toy snake; and (d) the neutral blocks used in Experiment 1; (e) two silk flowers, one pink, the other blue; and (f) two silk flowers, one purple, the other yellow. (The four flowers measured between 38 and $43 \mathrm{~cm}$ in length, including the green plastic stems.)

\section{Videotapes}

Four videotapes were used. Two showed the wild-born model; 2 showed the laboratory-born model. Two tapes ( 1 per model) showed a model reacting fearfully to the toy snake stimuli and nonfearfully to the flower stimuli (designated the $\mathrm{SN}+/ \mathrm{FL}-$ tapes). The remaining 2 tapes (one per model) showed a model reacting fearfully to the flower stimuli and nonfearfully to the toy snake stimuli (the FL+/ $\mathrm{SN}-$ tapes). All 4 tapes also depicted a model reacting nonfearfully to neutral stimuli. On these 4 videotapes, fear (or lack of fear) was manifested as in Experiment 1. That is, fear was indicated by a failure to reach over the stimulus object in the open Plexiglas box and by the display of fear behaviors over the course of the trial; lack of fear was indicated by reaching rapidly (2-3s) over the stimulus and by the absence of fear behaviors for the duration of the trial.

Each tape was comprised of 32 trials. Twenty were 5-s neutralobject trials ( $\mathrm{N}-$ ). The $2 \mathrm{FL}+/ \mathrm{SN}-$ tapes also contained six $60-\mathrm{sL}+$ trials in which the model apparently evinced extreme fear of the flowers and six 60 -s SN-trials in which the model apparently behaved nonfearfully in the presence of a toy snake. The $2 \mathrm{SN}+/ \mathrm{FL}-$ tapes contained $660-\mathrm{s} \mathrm{SN}+$ trials in which the model apparently evinced extreme fear of a toy snake and six $60-\mathrm{s} \mathrm{FL-} \mathrm{trials} \mathrm{in} \mathrm{which} \mathrm{the}$ model apparently behaved nonfearfully in the presence of the flowers. For each of the tapes, half of the flower trials showed the pink/blue flowers, and half showed the purple/yellow flowers; half of the toy snake trials showed the small toy snake, and half showed the big toy snake.

Because of the editing/splicing techniques used, the different tapes were identical in terms of the behavior exhibited by a given model; they differed only in what the model appeared to react to with fearful and nonfearful behavior. In the original unedited videotapes, fearful model "performances" were obtained by videotaping models reacting to the real snake and to the huge toy snake used in Experiment 1. These stimuli were replaced during the editing process with the appropriate toy snake or flower stimulus. In the original unedited videotapes, nonfearful model performances were obtained by videotaping models reaching over an empty Plexiglas box for food treats; the empty box was replaced during the editing process with a box containing the appropriate toy snake or flower stimulus. The $\mathrm{N}-$ trials did not need to be edited. The brief $\mathrm{N}-$ trials were included to maximize the likelihood that the observers "recognized" the setting that they were observing on the videotapes. That is, observers had extensive adaptation experience with neutral objects in the WGTA but not with the toy snake and flower stimuli. It should be noted the $\mathrm{FL}-$ and $\mathrm{SN}-$ trials differed from $\mathrm{N}-$ trials primarily in duration (60 vs. 5s).

For each tape, trial order was as follows: 4 neutral-object trials were followed by 6 snake and 6 flower trials. Snake and flower trials alternated with one another and were separated by further neutralobject trials. Following the last nonneutral stimulus presentation, five final neutral-object trials ensued. ITIs consisted of a 4-s period of "video black" (a blank, nonstatic image). The duration of each tape was approximately $18.5 \mathrm{~min}$.

The images of the snake and flower stimuli, as they appeared on the videotapes, were similar to one another in size, ranging from approximately 17 to $20 \mathrm{~cm}$ long. The screen image of the neutral blocks was approximately $3.2 \mathrm{~cm}$ wide, that of the model monkeys was approximately $18 \mathrm{~cm}$ tall, and that of the food treat was approximately $1 \mathrm{~cm}$ in diameter. Snake, flower, and neutral stimuli were always stationary.

\section{Procedure}

WGTA adaptation and pretest. The adaptation procedure was identical to that used in Experiment 1. Following adaptation, observers were pretested in the WGTA. The pretest procedure differed from

\footnotetext{
${ }^{3}$ Preliminary results of this study based on a subset of the monkeys presented here $(n=6)$ have previously been presented briefly in Mineka (1987), Mineka and Cook (1988), and Mineka and Tomarken (1989). Because of a difference in the way WGTA responses were averaged in Mineka (1987) and Mineka and Cook (1988), the graphed WGTA results in those two reports appear to indicate relatively greater mean responses than those shown in the present report. However, the discrepancy represents a difference in scale, not in actual response magnitude. Mineka and Tomarken (1989) reported median rather than mean WGTA performance.
} 
that followed for Experiment 1 only in the stimuli presented and the order of presentation. Five stimuli were presented: the big and small toy snakes, the pink/blue flowers, the purple/yellow flowers, and the neutral object. Presentation order was analogous to that used for Experiment 1, resulting in 18 trials in which each nonneutral stimulus was presented twice.

Circus adaptation and pretest. With the exception of the stimuli used, adaptation and pretest Circus sessions were conducted as in Experiment 1. During adaptation, the stimuli were 5 neutral abjects. During the pretest, the big and small toy snakes, the pink/blue flowers, the purple/yellow flowers, and the neutral object were used.

Observational conditioning. Following the WGTA and Circus pretests, observers were assigned to the $\mathrm{SN}+/ \mathrm{FL}-$ or $\mathrm{FL}+/ \mathrm{SN}-$ condition, and underwent 12 observational conditioning sessions over a 3- to 4-week period. During each session, $\mathrm{SN}+/ \mathrm{FL}-$ observers watched the $2 \mathrm{SN}+/ \mathrm{FL}$ - tapes in the WGTA setting, and $\mathrm{FL}+/ \mathrm{SN}-$ observers watched the $2 \mathrm{FL}+/ \mathrm{SN}-$ tapes. Systematic observation of observer behavior during conditioning was not possible.

Circus and WGTA posttests. Following the fourth observational conditioning session, observers were given a posttest in the Circus. This posttest was procedurally identical to the Circus pretest. This cycle of 4 conditioning sessions followed by a Circus posttest was repeated 2 more times so that observers received a total of 12 conditioning sessions and 3 Circus posttests. ${ }^{4}$

Following the final Circus posttest, observers received a WGTA posttest identical in procedure to the WGTA pretest with one exception. Following the first 18 trials, 4 additional trials were administered: 2 neutral-object and 2 real-snake trials (the neutral object and real snake were presented in alternation). These real-snake trials were the first occasion the observers saw the real snake.

\section{Data Analysis}

Two investigators scored fear behaviors over the course of the experiment. Interrater agreement was assessed during 3 WGTA posttests. Interrater agreement was $88 \%$; that is, 43 of the 49 behaviors recorded over the 66 trials were noted by both raters. If the instances for which the raters agreed no fear behaviors occurred were included in the assessment, agreement would exceed $99 \%$.

Data analysis was analogous to that performed for Experiment 1. Experimental hypotheses were tested with 6 sets of planned comparisons. Experimentwise alpha associated with each dependent measure was equivalent to what would have been yielded had we conducted 6 planned comparisons, each evaluated at $\alpha=.05$. The first 2 sets, one set per group, were composed of within-group contrasts, which focused on the expectation that responding to the CS+ and CS- did not differ at pretest; the third and fourth sets, one set for each group, were composed of within-group contrasts examining whether responding to the $\mathrm{CS}+$ and $\mathrm{CS}-$ changed as a result of conditioning; the fifth set was comprised of between-group contrasts examining group differences in the response to $\mathrm{CS}+$ and $\mathrm{CS}-$ at posttest; the sixth set included both within-group and between-group contrasts examining the response to the real snake $(R)$. (This last set was applied only to the WGTA measures because the real snake was not presented in the Circus apparatus.)

In Sets 1 and 2, CS+ $+_{\text {preces }}-\mathrm{CS}-_{\text {pretest }}$ (the CS+ was the mean response to the 2 flower stimuli for the $\mathrm{FL}+/ \mathrm{SN}-$ group and the mean response to the 2 toy snakes for the $\mathrm{SN}+/ \mathrm{FL}-$ group; and vice versa for the $\mathrm{CS}-$ ). In Sets 3 and 4, (a) $\mathrm{CS}+_{\text {positest }}-\mathrm{CS}+_{\text {pretest }}$, (b) $\mathrm{CS}-_{\text {posttest }}($ for $\mathrm{SN}+/ \mathrm{FL}-$ ) $-\mathrm{CS}-$ postest $($ for $\mathrm{FL}+/ \mathrm{SN}-$ ). In Set 6, (a, b) $\mathrm{R}-\mathrm{CS}+_{\text {postest, }}$, and (c, d) $\mathrm{R}-\mathrm{CS}-_{\text {postest }}$, (e) $\mathrm{R}_{\text {postest }}$ (for $\mathrm{SN}+$ / $\mathrm{CS}+{ }_{\text {postest }}$ (for $\mathrm{SN}+/ \mathrm{FL}-$ ) $-\mathrm{CS}+_{\text {postest }}($ for $\mathrm{FL}+/ \mathrm{SN}-$ ), and (b) $\mathrm{CS}-$ posttest (for $\mathrm{SN}+/ \mathrm{FL}-$ ) $-\mathrm{CS}-{ }_{\text {posttest }}$ (for $\mathrm{FL}+/ \mathrm{SN}-$ ). In Set 6 , (a, b) R - CS $+_{\text {posttest, }}$ and (c, d) R $-\mathrm{CS}-_{\text {postters }}$ (e) $\mathrm{R}_{\text {postest }}$ (for $\mathrm{SN}+/$ $\mathrm{FL}-$ ) $-\mathrm{R}_{\text {postiest }}$ (for $\mathrm{FL}+/ \mathrm{SN}-$ ). The critical $p$ value for a given contrast was .05 divided by the number of contrasts in the relevant set.

Comparisons involving the neutral stimulus were not used because it was thought that their inclusion would prove redundant. That is, two CSs were presented to each group, the toy snake (or flowers) and the neutral objects. The neutral object appeared to be the less appropriate of the two to use in planned comparisons. First, stimulus presentation parameters during conditioning (trial duration, number of trials, and so on) for the neutral trials differed substantially from those for the other two stimuli. Second, subjects had extensive prior exposure during adaptation to the neutral objects (but not to the toy snakes or flowers).

\section{Results}

In overview, observational conditioning resulted in the $\mathrm{SN}+/ \mathrm{FL}$ - group acquiring a fear of snake stimuli, but not of flower stimuli. By contrast, the $\mathrm{FL}+/ \mathrm{SN}-$ group did not show fear of either snake or flower stimuli following exposure to the videotapes.

\section{Observational Conditioning}

Incidental observations of the observer monkeys watching the videotapes were consistent with those obtained during Experiment 1.

\section{Circus}

A $2 \times 2 \times 3$ (Groups [FL+/SN- vs. $\mathrm{SN}+/ \mathrm{FL}-] \times$ Tests [pretest vs. average posttest] $\times$ Stimulus Objects [CS+, CS - , $\mathrm{N}-$ ]) mixed-design ANOVA examined observer compartment times during pretest and average posttest. A significant main effect for objects, $F(1,24)=10.74$, and a significant Groups $\times$ Tests $\times$ Objects interaction, $F(1,24)=4.69$, were revealed. Posttest values were averaged over the 3 posttest sessions in the foregoing ANOVA because, in a preliminary $2 \times 3 \times 3$ (Groups $\times$ Circus Posttest Sessions $\times$ Stimulus Objects) mixed-design ANOVA examining observer performance during the individual posttest sessions, neither the main effect for posttest sessions nor any interaction involving the sessions factor were significant. That is, the behavior of observers in both groups did not significantly change over the individual posttests.

Planned comparisons supported the contention that the $\mathrm{SN}+/ \mathrm{FL}-$ group acquired a fear of the toy snakes, whereas the $\mathrm{FL}+/ \mathrm{SN}-$ group did not acquire a fear of the flowers. The 2 groups did not differ in their response to the CS+ and CS- at pretest. The pretest-to-posttest decrease in mean com-

\footnotetext{
${ }^{4}$ Three of the observers in each group were tested after every second conditioning session instead of after every fourth session. Thus, these observers, although receiving the same number of conditioning sessions as the remaining observers, received twice as many Circus posttests (i.e., six vs. three). Because an examination of the data showed that the performance of these six-posttest observers was roughly comparable to that of the three-posttest behaviors, for purposes of data analysis only their second, fourth, and sixth posttests were used (i.e., those posttests that were conducted at the same points in time-relative to number of conditioning sessions received-as were the three posttests given the three-posttest observers).
} 
partment time with the toy snake (the decrease indicating increased fear) was marginally significant for the $\mathrm{SN}+/ \mathrm{FL}-$ observers, $p=.027$ (critical $p=.0167$ ). No such decrease occurred for the FL+/SN- group's CS+ (i.e., the flowers). Further, the two groups differed in their response to their respective $\mathrm{CS}+\mathrm{s}$ (but not $\mathrm{CS}-\mathrm{s}$ ) at posttest; the $\mathrm{SN}+/ \mathrm{FL}-$ observers spent significantly less time with the snake than did the $\mathrm{FL}+/ \mathrm{SN}-$ observers with the flowers. Neither group showed a pretest-to-posttest shift in responding to the CSFigure 4 depicts these results.

\section{WGTA}

Observer latency scores were analyzed by a $2 \times 2 \times 3$ (Groups [FL+/SN- vs. $\mathrm{SN}+/ \mathrm{FL}-] \times$ Tests [pretest vs. posttest] $\times$ Stimulus Objects [CS,$+ \mathrm{CS}-, \mathrm{N}-]$ ) mixed-design ANOVA. (ANOVAS for the two WGTA measures did not examine responses to the real snake because their inclusion would have resulted in an unbalanced design; i.e., responses to the real snake were measured only at posttest.) Analysis revealed a significant main effect for objects, $F(1,24)=18.98$, significant Groups $\times$ Tests, Groups $\times$ Objects, and Tests $\times$ Objects two-way interactions, $F(1,24)=4.97, F(1,24)=$ 3.84 , and $F(2,48)=10.51$, respectively, and a significant Groups $\times$ Tests $\times$ Objects interaction, $F(2,48)=6.17$.

Results of planned comparisons for latency were similar to those for Circus compartment time. The two groups did not differ in their response to $\mathrm{CS}+$ and $\mathrm{CS}-$ at pretest. The $\mathrm{SN}+1$ FL- observers showed a significant pretest-to-posttest increase in latency to the toy snake. No change in latency to the flowers occurred for the $\mathrm{FL}+/ \mathrm{SN}-$ observers. In addition, the two groups differed significantly in their response to their respective $\mathrm{CS}+\mathrm{s}$ (but not $\mathrm{CS}-\mathrm{s}$ ) at posttest: Latencies of the $\mathrm{SN}+/ \mathrm{FL}-$ observers to the toy snakes were longer than were latencies of the $\mathrm{FL}+/ \mathrm{SN}-$ observers to the flowers. Neither group showed a pretest-to-posttest shift in responding to the CS-. At posttest, both groups exhibited longer latencies to the real snake than to their respective CS-s (but not CS+s).

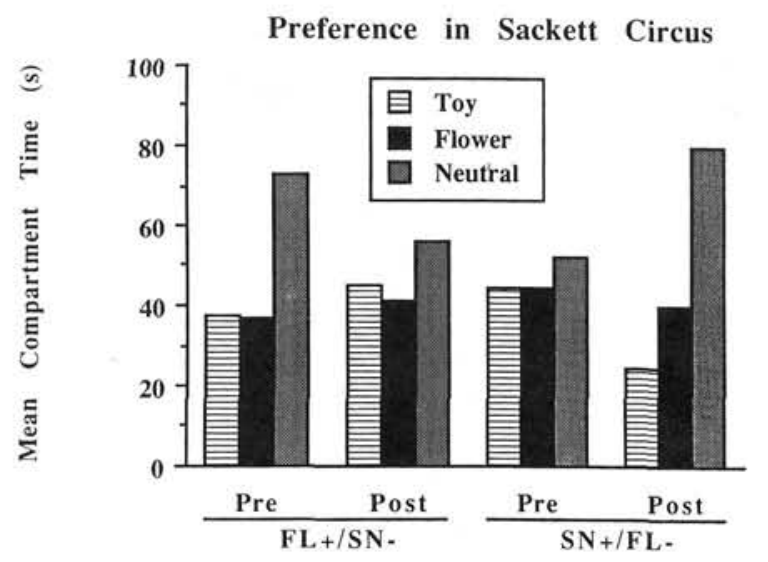

Figure 4. Mean compartment times in the Circus for three stimulus objects (toy snakes, flowers, and neutral object) for the $\mathrm{FL}+/ \mathrm{SN}-$ and $\mathrm{SN}+/ \mathrm{FL}$ - observers of Experiment 2 at pretest and posttest.
Mean latencies of the $\mathrm{SN}+/ \mathrm{FL}-$ subjects to the real snake were greater than those of the $\mathrm{FL}+/ \mathrm{SN}-$ subjects, but this difference was only marginally significant, $p=.027$ (critical $p=.01)$.

Observer disturbance scores were analyzed by a $2 \times 2 \times 3$ (Groups $\times$ Tests $\times$ Stimulus Objects) mixed-design ANOVA (analogous to the ANOVA for latency). Analysis revealed significant main effects for tests and objects, $F(1,24)=6.13$ and $F(2,48)=5.64$, respectively, and significant Groups $\times$ Objects and Tests $\times$ Objects two-way interactions, $F \mathrm{~s}(2,48)=5.04$ and 3.39 , respectively.

Results of planned comparisons were similar to those for the other measures. The two groups did not differ in their response to $\mathrm{CS}+$ and $\mathrm{CS}-$ at pretest. The $\mathrm{SN}+/ \mathrm{FL}-$ observers showed a significant pretest-to-posttest increase in disturbance to the toy snake. No change in disturbance to the flowers occurred for the $\mathrm{FL}+/ \mathrm{SN}-$ observers. In addition, the two groups differed significantly in their level of distress with their respective $\mathrm{CS}+\mathrm{s}$ (but not $\mathrm{CS}-\mathrm{s}$ ) at posttest: $\mathrm{SN}+/ \mathrm{FL}$ - observers displayed more distress with the toy snakes than did FL+/ $\mathrm{SN}-$ observers with the flowers. Neither group showed a pretest-to-posttest shift in responding to the CS-. At posttest, both groups exhibited greater distress in the presence of the real snake than with either the CS+ or CS-. Level of distress shown by the $\mathrm{SN}+/ \mathrm{FL}-$ subjects to the real snake did not significantly differ from that of the $\mathrm{FL}+/ \mathrm{SN}-$ subjects. Figures 5 and 6 depict results for the WGTA measures.

\section{Discussion}

The results of Experiment 2 support the inference of a selective association between fear-relevant stimuli and aversive outcomes. Specifically, rhesus monkeys appear to differentially associate fear-relevant CSs (toy snakes)-as opposed to fear-irrelevant CSs (flowers)-with vicariously observed USs (i.e., the fear responses of conspecifics). Similar results were attained with a very different species by Curio, Ernst, and Vieth (1978; see also Curio, 1988). They found that European blackbirds (Turdus merula) exhibited significantly higher levels of mobbing when the alarm cries of a conspecific were paired with a fear-relevant, predator-like, stuffed noisy friarbird (Philemon corniculatus) rather than a fear-irrelevant plastic bottle.

In the present experiment, fear of the CSs was first measured (in the Circus) after four conditioning sessions. Eight additional conditioning sessions did not appear to result in any additional increment in fear of the toy snake CS+ for the $\mathrm{SN}+/ \mathrm{FL}-$ observers. (Not surprisingly, the level of acquired fear to the toy snake was not quite as high as in Experiment 1 where the more salient-larger and moving-real and huge toy snakes were used during observational conditioning.) Given that no further increments in snake fear appeared to occur between Sessions 5 and 12 of observational conditioning for the $\mathrm{SN}+/ \mathrm{FL}-$ observers, it does not seem plausible to presume that the $\mathrm{FL}+/ \mathrm{SN}-$ observers failed to demonstrate a fear of the flower CS + simply because observational conditioning was not carried out long enough. Furthermore, the differential responding to toy snake stimuli does not appear to derive from a nonassociative selective sensitization process. 


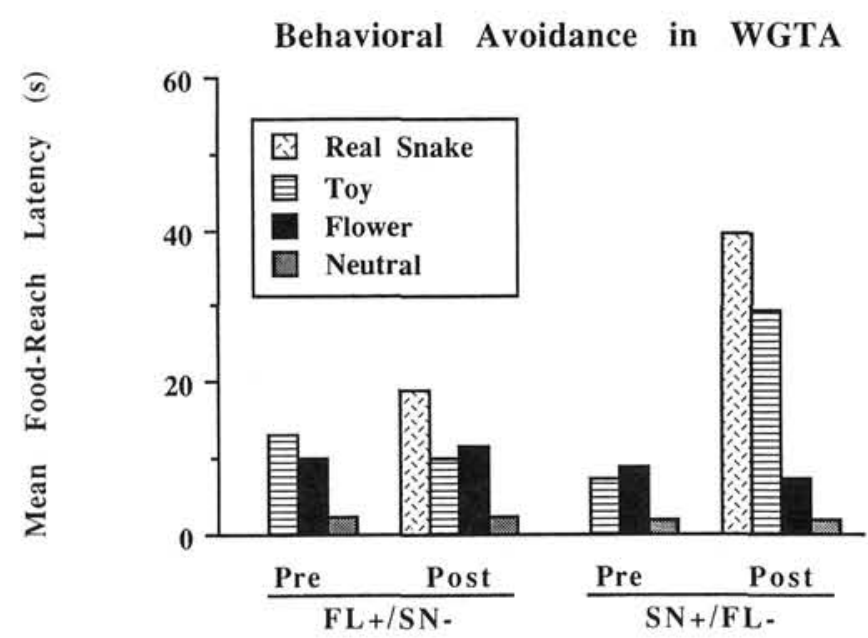

Figure 5. Mean food-reach latency in the Wisconsin General Test Apparatus (WGTA) in the presence of four stimulus objects (real snake, toy snakes, flowers, and neutral object) for the FL+/SN- and $\mathrm{SN}+/ \mathrm{FL}-$ observers of Experiment 2 at pretest and posttest.

If selective sensitization were responsible for the enhanced fear of toy snakes in the $\mathrm{SN}+/ \mathrm{FL}-$ observers, then the $\mathrm{FL}+1$ $\mathrm{SN}-$ observers, for whom toy snakes and the US were explicitly unpaired, should also have shown an enhanced fear of toy snakes.

Because observers were laboratory-raised animals with no prior experience with flowers or snakes, the differential associability cannot easily be ascribed to prior experiential differences of observers with the two stimulus classes. However, it is possible that specific stimulus properties possessed by the toy snakes, but not by the artificial flowers (e.g., eyes, forked tongues, sinuous shape), led observers to discriminate toy snakes as potentially animate objects. Further, one can assume that animate objects are less predictable and controllable than are inanimate objects. A large body of evidence has

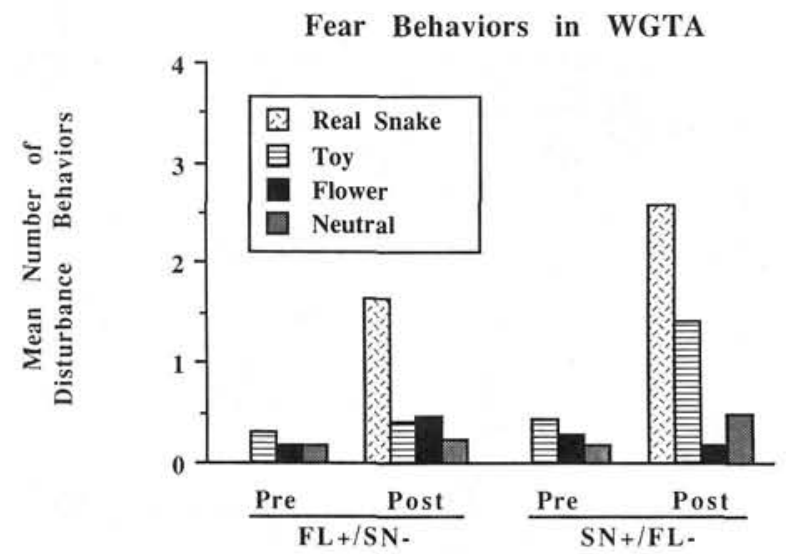

Figure 6. Mean number of disturbance behaviors exhibited in the Wisconsin General Test Apparatus (WGTA) in the presence of four stimulus objects (real snake, toy snakes, flowers, and neutral object) for the $\mathrm{FL}+/ \mathrm{SN}-$ and $\mathrm{SN}+/ \mathrm{FL}$ - observers of Experiment 2 at pretest and posttest. shown that more adverse consequences follow exposure to aversive stimuli that are unpredictable or uncontrollable than those that are controllable or predictable (see Maier \& Seligman, 1976; Mineka \& Hendersen, 1985; Overmier, Patterson, \& Wielkiewicz, 1980, for reviews). If observers had learned about the relatively unpredictable or uncontrollable nature of animate stimuli, they might have generalized between such stimuli and the toy snakes. Thus, the differential conditionability of the toy snakes could potentially reflect prior differential experiences with similar stimuli rather than a selective association (see Bandura, in press).

A recent study from this laboratory was designed to distinguish between these alternative accounts (Cook \& Mineka, 1989). In a procedure that paralleled that of Experiment 2, rhesus observers were exposed to videotapes of the conjoint fear response of a conspecific and one of two CS $+\mathrm{s}$, one fear relevant and the other fear irrelevant. However, the two CS+s were both toy animals-a fear-relevant crocodile and a fearirrelevant rabbit-that were presumably comparable in term of "animateness" (in contrast to toy snakes vs. flowers). Enhanced conditioning (fear acquisition) emerged only with the fear-relevant crocodile $\mathrm{CS}+$, arguing against an interpretation of the enhanced responding to snake $\mathrm{CS}+\mathrm{s}$ in the present experiment as being due solely to any animate qualities that toy snakes might possess.

The $\mathrm{SN}+/ \mathrm{FL}-$ observers demonstrated greater mean fear of the live snake than that manifested by the $\mathrm{FL}+/ \mathrm{SN}-$ observers, although these differences were not significant. Further, the fact that both groups exhibited elevated fear/ distress with the real snake relative to that shown with the $\mathrm{CS}+$ or $\mathrm{CS}-$, or both poses some interpretational difficulties. Indications of fear of the real snake by the $\mathrm{FL}+/ \mathrm{SN}-$ observers, in particular, may be a consequence of the highly novel nature of the real snake; that is, unlike the remaining stimuli, the real snake could and sometimes did exhibit movement during its presentation. In addition, at the time of the WGTA posttest, observers had had extensive prior experience with all the stimuli except the real snake (see Bronson, 1968; Gray, 1971, chap. 9; Russell, 1979). Congruent with this line of reasoning, observers in previous studies (e.g., Cook \& Mineka, 1987) have occasionally exhibited a level of disturbance to the real snake at pretest (the first time they see the real snake) that is not dissimilar to that shown by the $\mathrm{FL}+/ \mathrm{SN}-$ observers in posttest. In any case, it should be noted that considerations of responding to the real snake do not strongly impinge upon conclusions concerning a selective association between the toy snakes (presented during conditioning) and aversive USs.

Although the design of Experiment 2 controls for some nonassociative phenomena (e.g., selective sensitization), other nonassociative accounts of the results can be formulated. Specifically, the greater conditionability of toy snakes as opposed to flowers could be a consequence of differences in salience between the two CSs (see Mackintosh, 1974, chap. 2). Although the two stimuli appear superficially comparable in salience (if anything, that of the flowers appears somewhat greater to the human eye), it is nevertheless possible that for monkeys the salience of the flowers is lower, resulting in less conditioning to this stimulus. To discount this possibility, an experimental design is required that approximates that used 
by Öhman et al. (1976), which crossed the factors of CS fear relevance and US type (see earlier discussion). Applying this logic to the interpretation of Experiment 2 results, if it can be demonstrated that an alternative reinforcer is capable of supporting a level of conditioning to a videotaped flower that is as strong or stronger than that to a videotaped toy snake, then the differential salience explanation of the Experiment 2 findings will be contraindicated, and the inference of a selective association would be the more likely interpretation (see LoLordo, 1979a, 1979b; LoLordo \& Droungas, 1989).

Experiment 3 was designed with this goal in mind. The alternative reinforcer was appetitive as opposed to aversive. Although, ideally, the design of this study should parallel that of Experiment 2 as closely as possible, with the exception of the US used, Experiment 3 differed from Experiment 2 along a number of additional dimensions. The response was instrumental rather than a classically conditioned emotional response because extensive pilot work failed to provide a reliable paradigm for the classical conditioning of an appetitive response in rhesus monkeys (cf. D'Amato \& Buckiewicz, 1980; D'Amato, Buckiewicz, \& Puopolo, 1981). In addition, the paradigm did not involve observational conditioning.

\section{Experiment 3}

Experiment 3 used a variation of the PAN ambiguous-cue problem. PAN problems involve two stimulus pairs, PA and NA: On PA trials, a "positive" cue, $P$, which is consistently reinforced $\left(\mathbf{S}^{+}\right)$, is presented along with an "ambiguous" cue, $A$, which is nonreinforced when paired with P. On NA trials, a "negative" cue, $\mathrm{N}$, which is consistently nonreinforced $\left(\mathrm{S}^{-}\right)$, is presented along with the ambiguous cue, $A$, which is reinforced when paired with $\mathrm{N}$. PAN problems have been solved by a variety of species including rhesus monkeys (Boyer \& Polidora, 1972; Fletcher, Grogg, \& Garske, 1968; Leary, 1958).

Subjects were required to solve 2 separate PAN problems, one involving videotaped flower stimuli and a second involving videotaped snake stimuli. In the flower PAN problem, one flower served as $\mathrm{P}$, a second, distinct flower served as $\mathrm{N}$, and a geometric figure (a diamond) served as the $\mathrm{A}$ cue. Similarly, in the snake PAN problem, one snake served as P, a second, distinct snake served as $\mathbf{N}$, and a geometric figure (a square) served as the A cue. In essence, Experiment 3 involved four rather than two problems: two flower problems (one PA, one NA) and two snake problems (one PA, one NA). Figure 7 provides a representation of the PAN problems.

Given that the toy snake and flower stimuli presented during observational conditioning of Experiment 2 were videotaped, the $\mathrm{P}, \mathrm{A}$, and $\mathrm{N}$ stimuli were also videotaped. Furthermore, one of the flower stimuli used in Experiment 2 was used as the $\mathrm{N}$ stimulus in the flower PAN problem. Similarly, a toy snake that was identical to one used in Experiment 2 (except for color) was utilized as the $\mathrm{N}$ stimulus of the snake PAN problem. It was crucial for interpretative reasons to demonstrate that subjects in Experiment 3 could learn about these specific $\mathrm{N}$ stimuli. It was for this reason that the PAN design was adopted in preference to a simpler simultaneous discrimination design involving only $\mathrm{S}^{+}$versus $\mathrm{S}^{-}$, where it is possible for a subject to solve a problem by simply approaching $\mathrm{S}^{+}$or by avoiding $\mathrm{S}^{-}$. For example, if a simultaneous discrimination problem were used with a stimulus from Experiment 2 serving as the $\mathbf{S}^{-}$, any learning might result solely from the development of approach tendencies to $\mathrm{S}^{+}$. Alternatively, if the Experiment 2 stimulus served as the $\mathrm{S}^{+}$, then learning might stem solely from the development of avoidance tendencies to $S^{-}$. The PAN design obviates the possibility of an approach-only or avoidance-only solution to the discrimination problem because the subject cannot solve the problem by always approaching $P$ (because $P$ is absent on the NA trials) or by always avoiding $N$ (because $N$ is absent on PA trials). Instead, solution requires a change in the associative value of all stimulus elements of the problem, $P$, A, and N. (See Berch, 1974; Hall, 1980; Zeaman \& House, 1962, for more detailed theoretical analyses of the PAN ambiguous-cue problem.)

If the results of Experiment 3 indicate that the rate of response acquisition for the flower PAN problems is as fast or faster than the rate achieved for the snake problems, then salience differences between the stimulus categories (snake vs. flower) cannot easily account for the Experiment 2 results; instead, the selective association account of those findings appears the more likely explanation. Note that because the $\mathrm{N}$ stimuli were identical or highly similar to stimuli used in Experiment 2, contrasts involving the NA problems (i.e., snake-NA vs. flower-NA) are relatively more important than those involving PA problems (i.e., snake-PA vs. flower-PA).

\section{Method}

\section{Subjects}

Subjects were 13 laboratory-reared rhesus monkeys $(6$ males and 7 females) ranging in age from 5 to 9 years. All monkeys were living at the Harlow Primate Laboratory at the time of the experiment. However, of these 13 initial subjects, only 6 ( 3 males and 3 females ranging in age from 5 to 9 years) were able to solve the discrimination problems (see Results for details).

\section{Stimuli and Apparatus}

Discrimination training took place in the same WGTA used in the first two experiments. During training, a color monitor, connected to a VCR, was situated within the WGTA so that the subject could view the videotaped stimuli on the monitor's screen when the WGTA blind was raised by the experimenter. Both the monitor and VCR were those used in the prior experiments. Low-level white noise masked any extraneous noise occurring during sessions in the WGTA.

The stimulus pairs presented to subjects were on two videotapes. One videotape contained the trials constituting the flower PAN problem; the second contained the trials constituting the snake PAN problem. Each tape was comprised of 20 trials (10 PA and $10 \mathrm{NA}$ trials). The order of PA and NA trials was semirandom. For each trial, one of the two stimuli presented occupied the right half of the monitor's screen and the second stimulus occupied the left half. Stimulus location on the screen was counterbalanced. The background against which stimuli appeared was a uniform beige. Stimuli were separated from one another by a black vertical line (approximately $1 \mathrm{~cm}$ wide).

For the flower PAN problem, $\mathrm{P}$ was a circular arrangement (approximately $30.5 \mathrm{~cm}$ in diameter) of lavender chrysanthemums ("mums"). Two of the silk flowers used in Experiment 2-one yellow, the other pink-were $\mathrm{N}$. The $\mathrm{A}$ cue was a blue cardboard diamond 


\section{Snake Problems}

PA Problem NA Problem

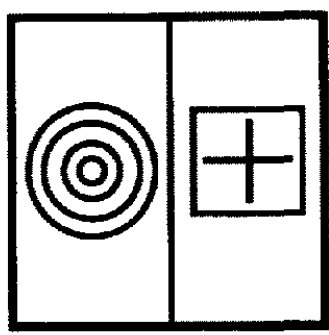

$\mathbf{P}$
A

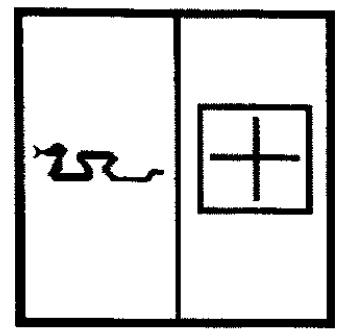

$\mathbf{N}$

A

Flower Problems

PA Problem

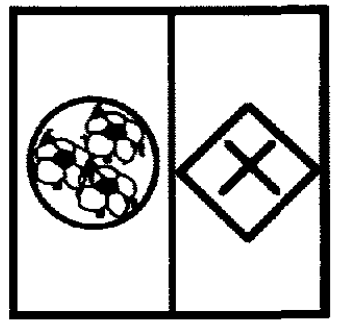

$\mathbf{P}$

A

Figure 7. Representation of snake and flower PAN problems (stimuli not drawn to scale). For the snake PAN problem (top panels), the concentric circles represent the coiled rattlesnake model, and the depiction of a snake (with a forked tongue) represents the sinuous toy snake. For the flower PAN problem (bottom panels), the circle enclosing three flowers represents the circular arrangement of mums, and the two flowers, each connected to a straight line, represent the two artificial flowers (including the stems).

(30.5 $\mathrm{cm}$ per side) with a white " $\mathrm{X}$ " occupying its center (each diagonal of the " $\mathrm{X}$ " was $25.4 \mathrm{~cm}$ long and $2.5 \mathrm{~cm}$ wide). For the snake PAN problem, $P$ was a brown ceramic model of a coiled timber rattlesnake (Crotalus horridus). The shape and size of the rattlesnake approximated that of the mums; that is, when viewed from above, the coiled snake presented a roughly circular profile, approximately $30.5 \mathrm{~cm}$ in diameter. $\mathrm{N}$ was a toy snake identical to the small toy snake of Experiment 2 except that it was colored a dark, drab green instead of brown to increase its discriminability from the brown rattlesnake $(\mathrm{P})$. The $A$ cue was a red cardboard square $(30.5 \mathrm{~cm}$ per side) with a white " + " occupying its center (the dimensions of the "+" were identical to those of the " $X$ " in the flower $A$ cue). Thus, the $A$ cue in the snake problem differed from the $A$ cue in flower problem in three dimensions: color (red vs. blue), orientation of the figure's perimeter (square vs. diamond), and orientation of the cross ("+" vs. "X").

$P, A$, and $N$ stimuli were selected and videotaped such that the screen images of the two $P$ stimuli were similar in shape and size, as were the images of the two $\mathrm{N}$ stimuli and those of the two A stimuli. Specifically, the camera angle during videotaping of the two $P$ stimuli was about 30 degrees above the horizontal surface the stimuli occupied. Hence, each $\mathrm{P}$ stimulus appeared on the screen as roughly ellipsoidal in shape with a major axis of approximately $14 \mathrm{~cm}$ and a minor axis of approximately $7.5 \mathrm{~cm}$. Camera angle during videotaping of the two $\mathrm{N}$ stimuli was also about 30 degrees above the horizontal surface they occupied. The screen images of the toy snake and of each of the two flowers were approximately $14 \mathrm{~cm}$ long. Finally, camera angle during videotaping of the two $A$ cues was 90 degrees (directly over the stimulus) so that the screen images for the A stimuli for the flower and snake problems appeared as diamond shaped and squared shaped, respectively; each side of each cue measured approximately $14 \mathrm{~cm}$.

Two hinged Plexiglas panels (each $45.7 \mathrm{~cm}$ high $\times 25.4 \mathrm{~cm}$ wide) were situated approximately $5 \mathrm{~cm}$ in front of the monitor's screen. One panel covered the left half of the screen, corresponding to the screen location where one member of a videotaped stimulus pair was presented. The second panel covered the right half of the screen, corresponding to the screen location where the remaining member of a stimulus pair was presented. Because the panels were clear, subjects could see the videotaped stimuli. These two panels served as manipulanda. A response consisted of pressing any part of a panel toward the screen approximately $0.3 \mathrm{~cm}$, which closed a microswitch. Pressing the panel covering the correct stimulus activated a treat dispenser that delivered a food treat with a latency of approximately $0.5 \mathrm{~s}$ to a 
recessed food magazine $(10.2 \mathrm{~cm}$ long $\times 7.6 \mathrm{~cm}$ high $\times 6.4 \mathrm{~cm}$ deep) located immediately beneath the pressed panel. (Two magazines were present, one corresponding to each panel.)

Two 100-mA, 28-V red miniature lamps were mounted, one at the right and one at the left edge of the screen. These lamps, when activated, blinked on and off (the light was interrupted 4.5 times per second and was on for $70 \%$ of a given second). These lamps served as additional cues for the subjects (see Procedure). Delivery of reinforcers and recording of subject responses were controlled by relay equipment located adjacent to the WGTA.

\section{Procedure}

For a given testing session, a subject received $40,80,120$, or 160 trials. The number of trials varied for a variety of reasons, including scheduling constraints and variable motivation to respond on the part of the subjects. Trials were presented in blocks of 40: Presentation of the flower PAN videotape (10 flower-PA and 10 flower-NA trials) was alternated with that of the snake PAN videotape (10 snake-PA and 10 snake-NA trials). The modal number of trials received per test session was 120 , that is, 30 trials per problem.

Each trial commenced with the appearance of $\mathrm{S}^{+}(\mathrm{P}$ or $\mathrm{A})$ and $\mathrm{S}^{-}$ ( $N$ or $A$ ) on the screen and the concurrent raising of the WGTA blind by experimenter, enabling the subject to respond. A correct response, pressing the panel covering $\mathrm{S}^{+}$, was reinforced with food. Subjects could continue to respond correctly for the duration of the 10-s trial, with each correct response being reinforced. Pressing the panel covering $\mathrm{S}^{-}$, an incorrect response, terminated the trial; that is, the blind was lowered, preventing the subject from making any further responses, correct or incorrect. If the subject made only correct responses or failed to make any response during a trial, the trial was terminated after $10 \mathrm{~s}$ again by the lowering of the blind. Thus, subjects were prevented from responding during the ITI. The minimum ITI length was $10 \mathrm{~s}$, the length of the video black segment separating each trial on the videotapes. However, when the subject responded to $\mathrm{S}^{-}$, prematurely terminating a trial, the effective length of the ITI was $10 \mathrm{~s}$ plus the amount of time left in the terminated trial. (Although it was possible for a subject to initially respond correctly and subsequently respond incorrectly during the same 10 -s trial, this rarely occurred. Such a pattern of responding was scored as an incorrect response. Further, failure to respond at all during a trial was scored as an incorrect response.)

During the first phase of discrimination learning, the correct panel was cued not only by the appearance of $\mathrm{S}^{+}$and $\mathrm{S}^{-}$on the screen, but additionally by the activation of the lamp adjacent to the correct panel. This phase continued until a subject responded correctly on at least $80 \%$ of 40 consecutive trials. The use of the lamps followed the results of pilot work that indicated that the PAN problems were very difficult to solve. It was thought that a "prompting" procedure involving the lamps would hasten learning: Responses initially would be controlled by the presumably more salient lamps, but stimulus control of responses would shift to the previously redundant videotaped stimuli when use of the lamps was discontinued. A number of experiments suggest that animals can learn about one set of redundant stimuli while responding on the basis of another set (e.g., Miles \& Jenkins, 1973; Turner, 1968; cited in Mackintosh, 1974, chap. 10; see Fletcher et al., 1968, for a description of a similar prompting procedure with rhesus monkeys solving a PAN problem).

Following this first phase, trials were presented without the lamps (prompts) cuing the correct response until three consecutive incorrect responses were made. If this happened, the use of the prompts was reinstituted until the subject made three consecutive correct responses, at which point the prompts were again discontinued. This procedure of initiating and discontinuing use of the prompts remained in effect for the remainder of the discrimination problem.
For each of the four problems, the learning criterion was the occurrence of a correct response on at least $80 \%$ of 30 consecutive nonprompted trials of a given problem. Because each problem was presented via a videotape that also contained the trials of another problem (viz., one tape contained the two snake problems; the other contained the two flower problems), if subjects reached criterion on one of those problems, they continued to receive trials for that problem until criterion was reached for the other problem on that tape (at which point both problems were discontinued).

\section{Results}

Only the results for those 6 subjects who were able to achieve criterion on the PAN problems are presented. None of the remaining 7 subjects achieved criterion for any of the problems in spite of receiving an extensive number of trials (over 1,000 in all cases). Nor did these subjects show tendencies toward superior performance for particular problems. Of these 7 subjects, 2 showed a pattern of responding that consisted of very rapidly pressing one of the two manipulanda at the outset of the trial. However, the choice of manipulanda never came under the control of the discriminative stimuli; hence, neither of these subjects ever responded such that more than $60 \%$ of their responses were correct over a 30 -trial block. For the other 5 of the 7 subjects not considered, the proportion of trials on which they responded correctly frequently approached zero as a result of frequent nonresponding. Figures 8 and 9 show the performance of 2 of the 6 successful subjects on the nonprompted trials for each of the four problems. Figure 8 shows the performance of a subject who achieved criteria for the four problems relatively quickly, whereas
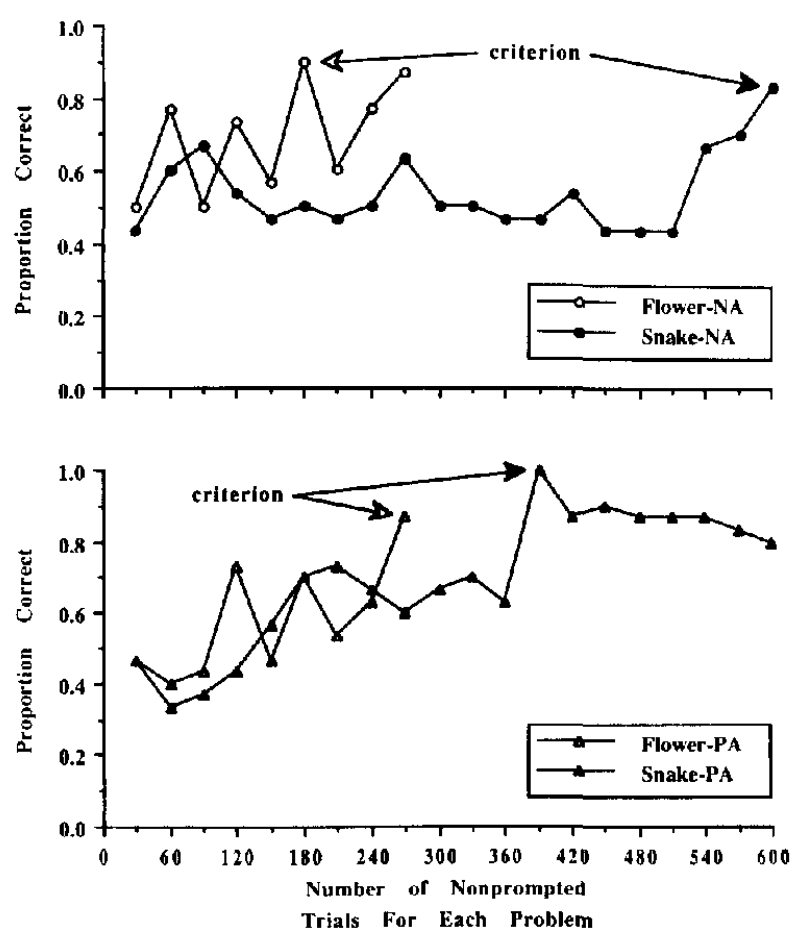

Figure 8. Proportion correct on each discrimination problem of Experiment 3 over successive blocks of 30 nonprompted trials for Subject AJ81. 
Figure 9 shows the performance of a subject who achieved criteria relatively slowly. For each problem, performance is indicated as proportion correct over successive blocks of 30 nonprompted trials.

Table 1 indicates the number of nonprompted trials each subject required to reach criterion for each of the four problems. Comparing the two flower problems, 3 of the 6 subjects showed faster acquisition on the NA than on the PA problem. For the two snake problems, 4 of the 6 subjects showed faster acquisition on the PA than on the NA problem. Wilcoxon tests showed that neither of these differences were significant, $T s \geq 9.00$.

Contrasting the two PA problems, 4 of the 6 subjects showed faster acquisition on the snake problem than on the flower problem. For the two NA problems, 4 of the 6 subjects showed faster acquisition on the flower problem than on the snake problem. Neither of these two differences were significant, $T \mathrm{~s} \geq 8.00$. Lack of differences in trials in criterion was further confirmed by the nonsignificance of a Friedman test statistic contrasting all four problems, $\chi_{r}^{2}(3, N=6)=1.00$.

Table 1 also shows the total number of trials to reach criterion (i.e., prompted and nonprompted trials combined) for each of the four problems. The pattern of results was extremely similar to that obtained when considering only the nonprompted trials: Wilcoxon and Friedman analyses failed to uncover any significant differences among the four problems, $T s \geq 8.00, \chi_{r}^{2}(3, N=6)=1.00$.

Finally, it might be argued that, because trial order was fixed for both the tape containing the snake problems and that containing the flower problems, subjects who successfully achieved criterion may have done so by having memorized trial order rather than by responding on the basis of the conditional relationships between the stimuli set up by the PAN design. We consider this possibility unlikely, however.
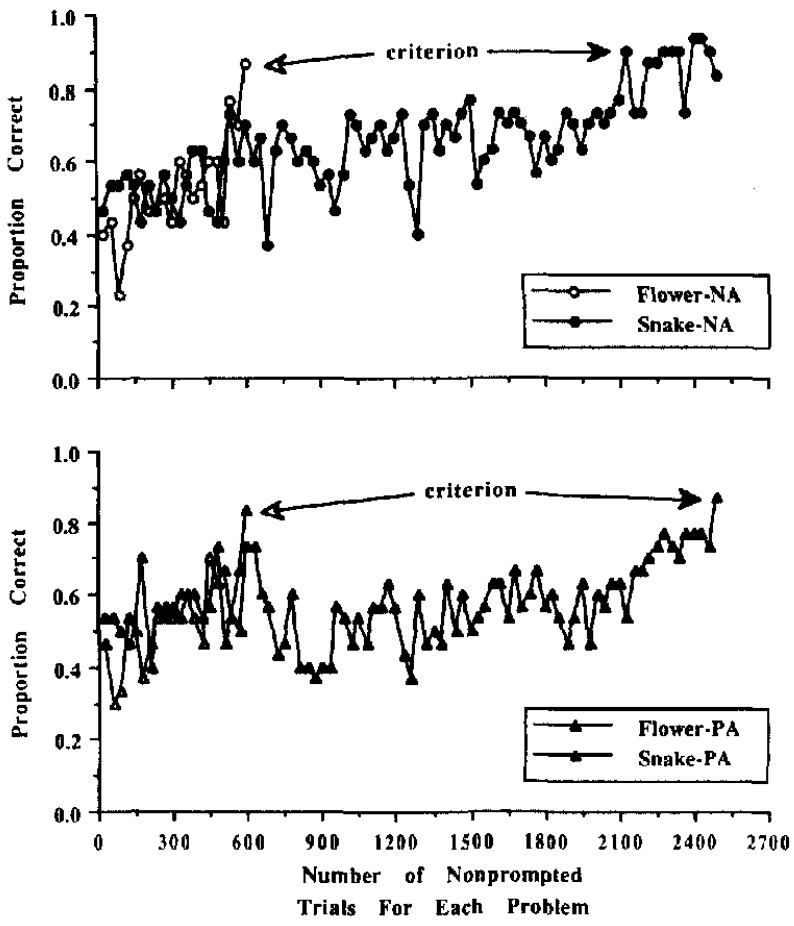

Figure 9. Proportion correct on each discrimination problem of Experiment 3 over successive blocks of 30 nonprompted trials for Subject AG21.

If subjects had memorized trial order, one would expect to see comparable rates of acquisition for the PA and NA problems within each tape (the order of PA and NA trials within each tape was pseudorandom). Although as noted there

Table 1

Number of Nonprompted Trials and Total Trials Required by Subjects to Reach Criterion for Each of the Four Problems in Experiment 3

\begin{tabular}{|c|c|c|c|c|c|c|}
\hline \multirow[b]{2}{*}{ Subject } & \multicolumn{2}{|c|}{ PA problems } & \multicolumn{2}{|c|}{ NA problems } & \multicolumn{2}{|c|}{ PA vs. NA } \\
\hline & Snake & Flower & Snake & Flower & Snake $^{a}$ & Flower \\
\hline \multicolumn{7}{|l|}{ AI17 } \\
\hline Nonprompted & 70 & 270 & 630 & 340 & $1134,138.63^{*}$ & $612,0.62$ \\
\hline Total & 202 & 430 & 777 & 492 & & \\
\hline \multicolumn{7}{|l|}{ AJ81 } \\
\hline Nonprompted & 380 & 270 & 600 & 170 & $1080,32.72^{*}$ & $486,7.30^{*}$ \\
\hline Total & 460 & 346 & 681 & 239 & & \\
\hline \multicolumn{7}{|l|}{ AK 16} \\
\hline Nonprompted & 210 & 270 & 240 & 140 & $432,4.53^{*}$ & $486,5.85^{*}$ \\
\hline Total & 307 & 368 & 342 & 234 & & \\
\hline \multicolumn{7}{|l|}{$\mathrm{AG} 21$} \\
\hline Nonprompted & 2,470 & 590 & 2,110 & 580 & $4446,36.59^{*}$ & $1062,0.22$ \\
\hline Total & 3,226 & 1,262 & 2,849 & 1,247 & & \\
\hline \multicolumn{7}{|l|}{ AG41 } \\
\hline Nonprompted & 440 & 1,280 & 490 & 1,350 & $882,8.75^{*}$ & $2430,1.39$ \\
\hline Total & 1,479 & 2,432 & 1,530 & 2,492 & & \\
\hline \multicolumn{7}{|l|}{ Al08 } \\
\hline Nonprompted & 2,040 & 2,260 & 1,800 & 3,050 & $3636,15.98^{*}$ & $5364,72.04^{*}$ \\
\hline Total & 3,306 & 3,835 & 3,079 & 4,597 & & \\
\hline
\end{tabular}

Values are denominator degrees of freedom followed by $F$ ratio for PA versus NA comparison. Numerator degrees of freedom are always 1 .

$* p<.05$. 
was no overall significant difference between PA and NA problems in number of trials to solution, individual subjects often exhibited striking differences in the rate of solution of PA versus NA problems. For example, Subject AI17 required 560 more trials to reach criterion for the NA problem on the snake tape than for the PA problem on the same tape. By contrast, Subject AG21 required 360 more trials to reach criterion for the PA problem on the snake tape than for the NA problem on the snake tape (see Table 1).

Single-subject ANOVAS were used to statistically evaluate differences in rate of solution of PA versus NA problems. Anderson (1982, chap. 2) reviewed the rationale and general use of such designs in situations where the locus of theoretical interest lies in the performance of the individual subject, as is the case here. Two single-subject ANOvas were conducted for each of the 6 subjects, one examining the snake-PA and snakeNA problems, the other examining the flower-PA and flowerNA problems. Design factors were problem type (PA vs. NA) and trial blocks (ten trials per block). To generate a suitable nonzero error term for each ANOVA, the responses made by a subject on each trial were treated as if they had been made by different subjects (cf. Anderson, 1982, chap. 2). Table 1 summarizes the outcomes of these analyses: 9 of the 12 yielded a significant main effect for problem type, thereby supporting the initial impression of individual variation in PA versus NA performance.

\section{Discussion}

The results of Experiment 3 demonstrate that flowers are not incapable of supporting conditioning under all circumstances. All 6 of the subjects that showed signs of learning any of the problems were able to solve those problems in which flowers constituted the $\mathrm{P}$ and $\mathrm{N}$ stimuli. More important, the results failed to reveal any consistent difference across subjects in the rate of solution of flower versus snake discrimination problems. Specifically, for the two PA problems, 2 of the 6 subjects showed faster acquisition on the flower problem than on the snake problem. For the two NA problems, 4 of the 6 subjects showed faster acquisition on the flower problem than on the snake problem. Because the $\mathrm{N}$ stimuli were identical or highly similar to stimuli used in Experiment 2, the latter contrast is relatively more important in drawing conclusions. Thus, it appears that the superior associability of snakes and reinforcers is specific to aversive rather than appetitive outcomes; that is, the snake-aversive US association seen in Experiment 2 is a selective one.

However, it should be acknowledged that, because the designs of Experiments 2 and 3 were not entirely parallel, this conclusion is somewhat less definitive than would be desirable. Specifically, Experiment 2 used a discriminative observational classical conditioning design, whereas Experiment 3 used a discriminative appetitive operant paradigm that did not involve observational learning. We used this design in Experiment 3 because extensive pilot work had failed to provide a paradigm that produced discriminative classical conditioning with an appetitive reinforcer and videotaped stimuli. Use of the PAN paradigm was, in essence, a compromise that allowed us to demonstrate that monkeys could learn about the same videotaped stimuli used in Experiment 2 in an appetitive context, albeit with a quite different experimental design.

Although individual subjects often showed differences in rate of solution of PA and NA problems, there was no overall trend for PA performance to exceed NA performance or vice versa. This lack of a consistent difference in rate of solution of PA versus NA problems stands in contrast to the results of other PAN discrimination studies. In general, given P, A, and $\mathrm{N}$ stimuli of approximately equal salience or spatial complexity, NA performance should exceed PA performance (see Berch, 1974). The various theories advanced to explain this outcome posit that the degree to which approach (or avoidance) tendencies are conditioned to objects is proportional to their salience/spatial complexity. Over a number of trials, there should exist a net tendency to approach $\mathrm{P}$ and avoid $\mathrm{N}$. Additionally, because the effects of reward are supposedly relatively greater than those of nonreward, there should also exist a net tendency to approach $A$, although this tendency is somewhat weaker than the tendency to approach $P$. The poorer PA performance is therefore a consequence of the competing approach tendencies between the $\mathrm{P}$ and $\mathrm{A}$ cues; no such competing tendencies exist for the NA problem. By manipulating stimulus salience/complexity, one can obtain the reverse outcome. That is, by making $A$ less salient than $P$ and $\mathrm{N}$, performance on PA problems exceeds that on NA problems, supposedly because A acquires less excitatory strength and hence competes less with P on PA trials than in the case where the three stimuli are equally salient (e.g., Boyer \& Polidora, 1972; Boyer, Polidora, Fletcher, \& Woodruff, 1966).

In the present experiment, the $\mathrm{P}$ and $\mathrm{N}$ stimuli were presumably more salient than the $A$ stimuli so that one might expect PA performance to exceed NA performance. However, as noted, a clear trend of this sort was not found in the data. It may be that by requiring subjects to solve two PAN problems in alternation rather than on a strict successive basis as has been done in previous studies (e.g., Boyer \& Polidora, 1972), some sort of interaction between the two problems resulted, leading to the present pattern of results.

\section{General Discussion}

Considered together, the results of Experiments 2 and 3 support the hypothesis that the snake-aversive outcome association is selective. That is, the results imply a differential associability between fear-relevant CSs (as opposed to fearirrelevant CSs) and vicariously observed USs (the fear responses of conspecifics). Further, the results of Experiment 3 argue against one nonassociative account of the differential responding to fear-relevant stimuli, namely that parametric differences between the two stimulus classes along some dimension such as salience or discriminability account for the differences in fear conditioning. If one presumes that the greater ease of conditioning with snake CSs is a consequence of their greater salience (relative to that of flowers), a similar difference in conditioning should have emerged in the PAN experiment (i.e., superior performance on snake problems). As noted, however, such was not the case. 
Not all nonassociative accounts are completely discounted by the present results. For example, it is possible that the flower-aversive US association for the $\mathrm{FL}+/ \mathrm{SN}-$ group in Experiment 2 was equivalent in strength to that of the snakeaversive US association for the $\mathrm{SN}+/ \mathrm{FL}-$ group, but that overt expression of the former was for some reason not manifested. Alternative experimental procedures (e.g., blocking or second-order conditioning) might have revealed conditioning to the "less relevant" stimulus class. Although we cannot definitively rule this possibility out, we do not consider it likely. Holland (1977) noted that whereas one dependent measure may fail to uncover such a "silent" association, another may. In Experiment 2, three dependent measures indexed fear of the CSs. Yet all of these measures agreed in indicating that, on average, no significant conditioning to the fear-irrelevant CS+ occurred.

The difficulty in establishing that associations are selective should by this point be apparent. Indeed, one review (Mackintosh, 1983, chap. 8) concluded at the time that, despite the voluminous literature, there existed compelling evidence for the selective nature of only two phenomena: (a) the association between gustatory cues and internal malaise (Garcia \& Koelling, 1966; Miller \& Domjan, 1981), and (b) the relative ease of establishing visual stimuli as signals for appetitive events and auditory stimuli as signals for aversive events in pigeons (Foree \& LoLordo, 1973; LoLordo \& Furrow, 1976; Shapiro, Jacobs, \& LoLordo, 1980; Shapiro \& LoLordo, 1982). Therefore, that the results of the present experiments do not provide absolutely definitive proof of the selectivity of the association examined should not be too surprising.

The present experimental results also have implications for posited ecologically oriented functional accounts of the snakeaversive outcome association. Ecologically oriented accounts of selective associations have posited that they have an evolutionary/genetic basis. For example, according to Seligman (1970, 1971), humans are presumably "prepared" to associate certain classes of stimuli (e.g., snakes) with aversive consequences because their mammalian ancestors, who easily required these fears, possessed a selective advantage relative to their contemporaries who did not. The results of Experiments 2 and 3 are consistent with this position. We should note, however, that theories such as Seligman's rest on premises concerning the adaptive function and phylogenetic history of the target behaviors/associations. For example, hypotheses regarding the adaptive function of easily acquired snake fear presume a predatory relation between snakes (or reptiles in general) and primates. Although field observations have verified that snakes occasionally prey upon several primate species (e.g., Heymann, 1987; van Schaik, van Noordwijk, de Boer, \& den Tonkelaar, 1983), estimated predation rates appear low; thus, the extent that such predation affects primate behavior remains unclear. (See Anderson, 1986, Cheney \& Wrangham, 1987, for recent reviews presenting contrasting viewpoints on the thesis that predation is and has been a selective force in the determination of primate behavior.)

In spite of this caveat, there are still reasons for believing that snake fear is in fact adaptive. For example, one might concede that the lack of data does, in fact, represent a genuinely low predation risk (as opposed to a methodological problem in data acquisition). It is possible, however, that more intense predation by snakes in the phylogenetic past of primate species has resulted in the "canalized" development of antisnake behavior; that is, such behavior might now persist over periods of relaxed selection (see Coss \& Owings, 1985; Öhman et al., 1985; Waddington, 1957). Alternatively, it is possible that snakes have exerted a significant influence on primate behavior that is not reflected in the current predation rate because the selection pressure in question has led to effective defenses against snakes. Indeed, the observation that snake fear is so prevalent among primate species (see introduction) is consistent with this hypothesis.

Given the fruitful employment of comparative strategies by evolutionary biologists in addressing issues of adaptation and phylogeny (see Hailman, 1976, for a general discussion of the comparative method), a number of writers have proposed their use in the investigation of constraint/selective association phenomena (e.g., Domjan \& Galef, 1983; Johnston, 1981). Domjan and Galef (1983), for example, outlined a strategy that includes, first, the identification of different selective pressures acting on phylogenetically similar forms; second, the formation of hypotheses concerning different associative processes likely to stem from the observed selective pressures; and third, demonstration of a correlation between behavioral elaborations and selective pressures. (Note that by observing the first two steps, the commonly observed ex post facto nature that frequently characterizes theorizing about the phylogeny of target behaviors is avoided.) Application of this methodology to the question of easily acquired snake fear by primates might begin by contrasting two primate populations, only one of which coevolved with predatory snakes. Given the hypothesis that the selective associability of snakes with aversive consequences represents an adaptive behavior shaped by natural selection, one might not expect a selective association to be manifest in the population that evolved in an environment free of predatory snakes.

In conclusion, the present studies support the hypothesis that the observed differential conditioning involving snakes and aversive conspecific fear responses represents a selective association. Moreover, the experimental findings extend the range of our knowledge concerning the conditions under which vicarious transmission of fear may occur by demonstrating such transmission in the case where videotaped rather than actual model performances are used. In addition, the present methodology provides a framework that can be used in addressing further questions regarding the possible role natural selection has played in mediating the ease with which snake fear is acquired by primates.

\section{References}

Anderson, C. (1986). Predation and primate evolution. Primates, 27, 15-39.

Anderson, N. (1982). Methods of information integration theory. San Diego, CA: Academic Press.

Bandura, A. (in press). Social cognitive theory and social referencing. In S. Feinman (Ed.), Social referencing and social construction of reality. New York: Plenum Press.

Bartecki, U., \& Heymann, E. (1987). Field observation of snake- 
mobbing in a group of saddle-back tamarins, Saguinus fuscicollis nigrifrons. Folia Primatologica 48, 199-202.

Berch, D. (1974). A theoretical analysis of the PAN ambiguous-cue problem. Learning and Motivation, 5, 135-148.

Boik, R. (1981). A priori tests in repeated measures designs: Effects of nonsphericity. Psychometrika, 46, 241-255.

Boinski, S. (1988). Use of a club by a wild white-faced capuchin (Cebus capucinus) to attack a venomous snake (Bothrops asper). American Journal of Primatology, 14, 177-179.

Boyer, W., \& Polidora, V. (1972). An analysis of the solution of PAN ambiguous-cue problems by rhesus monkeys. Learning and Motivation, 3, 325-333.

Boyer, W., Polidora, V., Fletcher, H., \& Woodruff, B. (1966). Monkeys' performance on ambiguous-cue problem. Perceptual and Motor Skills, 22, 883-888.

Bronson, G. (1968). The fear of novelty. Psychological Bulletin, 69, 350-358.

Capitanio, J., Boccia, M., \& Colaiannia, D. (1985). The influence of rank on affect perception by pigtailed macaques (Macaca nemestrina). American Journal of Primatology, 8, 53-59.

Cheney, D., \& Wrangham, R. (1987). Predation. In B. Smuts, D. Cheney, R. Seyfarth, R. Wrangham, \& T. Struhsaker (Eds.), Primate societies (pp. 227-239). Chicago: University of Chicago Press.

Cook, E., Hodes, R., \& Lang, P. (1986). Preparedness and phobia: Effects of stimulus content on human visceral conditioning. Journal of Abnormal Psychology, 95, 195-207.

Cook, M., \& Mineka, S. (1987). Second-order conditioning and overshadowing in the observational conditioning of fear in monkeys. Behaviour Research and Therapy, 25, 349-364.

Cook, M., \& Mineka, S. (1989). Observational conditioning of fear to fear-relevant versus fear-irrelevant stimuli in rhesus monkeys. Journal of Abnormal Psychology, 98, 448-459.

Cook, M., Mineka, S., Wolkenstein, B., \& Laitsch, K. (1985). Observational conditioning of snake fear in unrelated rhesus monkeys. Journal of Abnormal Psychology 94, 591-610.

Coss, R., \& Owings, D. (1985). Restraints on ground squirrel antipredator behavior: Adjustments over multiple time scales. In T. Johnston \& A. Pietrewicz (Eds.), Issues in the ecological study of learning (pp. 167-200). Hillsdale, NJ: Erlbaum.

Curio, E. (1988). Cultural transmission of enemy recognition by birds. In T. Zentall \& B. Galef (Eds.), Social learning: Psychological and biological perspectives (pp. 75-97). Hillsdale, NJ: Erlbaum.

Curio, E., Ernst, U., \& Vieth, W. (1978). The adaptive significance of avian mobbing: II. Cultural transmission of enemy recognition in blackbirds: Effectiveness and some constraints. Zeitschrift Tierpsychologie, 48, 184-202.

D'Amato, M., \& Buckiewicz, J. (1980). Long-delay, one-trial conditioned preference and retention in monkeys (Cebus apella). Animal Learning and Behavior, 8, 359-362.

D'Amato, M., Buckiewicz, J., \& Puopolo, M. (1981). Long-delay spatial discrimination learning in monkeys (Cebus apella). Bulletin of the Psychonomic Society, 18, 85-88.

Delprato, D. (1980). Hereditary determinants of fears and phobias. Behavior Therapy, 11, 79-103.

De Silva, P., Rachman, S., \& Seligman, M. (1977). Prepared phobias and obsessions: Therapeutic outcome. Behaviour Research and Therapy, 15, 65-77.

Domjan, M. (1983). Biological constraints on instrumental and classical conditioning: Implications for general process theory. In G. Bower (Ed.), The psychology of learning and motivation (Vol. 17, pp. 215-277). San Diego, CA: Academic Press.

Domjan, M., \& Galef, B. (1983). Biological constraints on instrumental and classical conditioning: Retrospect and prospect. Animal Learning and Behavior, 11, 151-161.

Dunn, O. (1961). Multiple comparisons among means. Journal of the American Statistical Association, 56, 52-64.
Fletcher, H., Grogg, T., \& Garske, J. (1968). Ambiguous-cue problem performance of children, retardates, and monkeys. Journal of Comparative and Physiological Psychology, 66, 477-482.

Foree, D., \& LoLordo, V. (1973). Attention in the pigeon: Differential effects of food-getting versus shock-avoidance procedures. Journal of Comparative and Physiological Psychology, 85, 551-558.

Garcia, J., \& Koelling, R. (1966). Relation of cue to consequence in avoidance learning. Psychonomic Science, 4, 123-124.

Gray, J. (1971). The psychology of fear and stress. New York: McGraw-Hill.

Greenhouse, S., \& Geisser, S. (1959). On methods in the analysis of profile data. Psychometrika, 24, 95-112.

Hailman, J. (1976). Uses of the comparative study of behavior. In R. Masterton, W. Hodos, \& H. Jerison (Eds.), Evolution, brain, and behavior: Persistent problems (pp. 13-22). Hillsdale, NJ: Erlbaum.

Hall, G. (1980). An investigation of ambiguous-cue learning in pigeons. Animal Learning and Behavior, 8, 282-286.

Harlow, H. (1949). The formation of learning sets. Psychological Review, 56, 51-65.

Heymann, E. (1987). A field observation of predation on a moustached tamarin (Saguinus mystax) by an anaconda. International Journal of Primatology, 8, 193-195.

Holland, P. (1977). Conditioned stimulus as a determinant of the form of the Pavlovian conditioned response. Journal of Experimental Psychology: Animal Behavior Processes, 3, 77-104.

Hygge, S., \& Ohman, A. (1978). Modeling processes in the acquisition of fears: Vicarious electrodermal conditioning to fear-relevant stimuli. Journal of Personality and Social Psychology, 36, 271-279.

Johnston, T. (1981). Contrasting approaches to a theory of learning. Behavioral and Brain Sciences, 4, 125-173.

Johnston, T., \& Pietrewicz, A. (1985). Issues in the ecological study of learning. Hillsdale, NJ: Erlbaum.

Joslin, J., Fletcher, H., \& Emlen, J. (1964). A comparison of the responses to snakes of lab- and wild-reared rhesus monkeys. Animal Behavior, 12, 348-352.

Lande, J., Higley, J., Snowdon, C., Goy, R., \& Suomi, S. (1985). Elicitors of parental care in rhesus monkeys [Abstract]. American Journal of Primatology, 8, 349.

Lang, P. (1968). Fear reduction and fear behavior: Problems in treating a construct. In J. Shlein (Ed.), Research in psychotherapy (Vol. 3, pp. 90-102). Washington, DC: American Psychological Association.

Lang, P. (1971) The application of psychophysiological methods to the study of psychotherapy and behavior modification. In A. Bergin \& S. Garfield (Eds.), Handbook of psychotherapy and behavior change: An empirical analysis (pp. 75-125). New York: Wiley.

Leary, R. (1958). The learning of ambiguous cue-problems by monkeys. American Journal of Psychology, 71, 718-724.

LoLordo, V. (1979a). Constraints on learning. In M. Bitterman, V. LoLordo, J. Overmier, \& M. Rashotte. (Eds.), Animal learning: Survey and analysis (pp. 473-504). New York: Plenum Press.

LoLordo, V. (1979b). Selective associations. In A. Dickinson \& R. Boakes (Eds.), Mechanisms of learning and motivation: $A$ memorial to Jerzy Konorski (pp. 367-398). Hillsdale, NJ: Erlbaum.

LoLordo, V., \& Droungas, A. (1989). Selective associations and adaptive specializations: Food aversion and phobias. In S. Klein \& R. Mowrer (Eds.), Contemporary learning theories: Instrumental conditioning theory and the impact of biological constraints on learning (pp. 145-179). Hillsdale, NJ: Erlbaum.

LoLordo, V., \& Furrow, D. (1976). Control by the auditory or the visual element of a compound discriminative stimulus: Effects of feedback. Journal of the Experimental Analysis of Behavior, 25. 251-256.

Mackintosh, N. (1974). The psychology of animal learning. San Diego, CA: Academic Press.

Mackintosh, N. (1983). Conditioning and associative learning. New 
York: Oxford University Press.

Maier, S., \& Seligman, M. (1976). Learned helplessness: Theory and evidence. Journal of Experimental Psychology: General, 105. 3-46.

Marks, I. (1987). Fears, phobias, and rituals: Panic, anxiety, and their disorders. New York: Oxford University Press.

Maxwell, S. (1980). Pairwise multiple comparisons in repeated measures designs. Journal of Educational Statistics. 5, 269-287.

McNally, R. (1987). Preparedness and phobias: A review. Psychological Bulletin, 101, 283-303.

Miles, C., \& Jenkins, H. (1973). Overshadowing in operant conditioning as a function of discriminability. Learning and Motivation. 4, 11-27.

Miller, V., \& Domjan, M. (1981). Specificity of cue to consequence in aversion learning in the rat: Control for US-induced differential orientations. Animal Learning and Behavior, 9, 339-345.

Mineka, S. (1979). The role of fear in theories of avoidance, flooding, and extinction. Psychological Bulletin, 86, 985-1010.

Mineka, S. (1985). Animal models of anxiety-based disorders: Their usefulness and limitations. In A. Tuma \& J. Maser (Eds.), Anxiety and the anxiety disorders (pp. 199-244). Hillsdale, NJ: Erlbaum.

Mineka, S. (1987). A primate model of phobic fears. In H. Eysenck \& I. Martin (Eds.), Theoretical foundations of behavior therapy (pp. 81-111). New York: Plenum Press.

Mineka, S., \& Cook, M. (1986). Immunization against the observational conditioning of snake fear in rhesus monkeys. Journal of Abnormal Psychology, 95, 307-318.

Mineka, S., \& Cook, M. (1988). Social learning and the acquisition of snake fear in monkeys. In T. Zentall \& B. Galef (Eds.), Social learning: Psychological and biological perspectives (pp. 51-73). Hillsdale, NJ: Erlbaum.

Mineka, S., Davidson, M., Cook, M., \& Keir, R. (1984). Observational conditioning of snake fear in rhesus monkeys. Journal of Abnormal Psychology, 93, 355-372.

Mineka, S., \& Henderson, R. (1985). Controllability and predictability in acquired motivation. Annual Review of Psychology, 36, 495530.

Mineka, S., Keir, R., \& Price, V. (1980). Fear of snakes in wild- and lab-reared rhesus monkeys. Animal Learning and Behavior, 8, 653663.

Mineka, S., \& Tomarken, A. (1989). The role of cognitive biases in the origins and maintenance of fear and anxiety disorders. In $\mathrm{T}$. Archer \& L.-G. Nilsson (Eds.), Aversion, avoidance, and anxiety: Perspectives on aversively motivated behavior (pp. 195-221). Hillsdale, NJ: Erlbaum.

Öhman, A. (1986). Face the beast and fear the face: Animal and social fears as prototypes for evolutionary analyses of emotion. Psychophysiology, 23, 123-145.

Öhman, A., Dimberg, U., \& Öst, L.-G. (1985). Biological constraints on the learned fear response. In S. Reiss \& R. Bootzin (Eds.), Theoretical issues in behavior therapy (pp. 123-175). San Diego, CA: Academic Press.

Öhman, A., Fredrikson, M., \& Hugdahl, K. (1978). Orienting and defensive responding in the electrodermal system: Palmar-dorsal differences and recovery rate during conditioning to potentially phobic stimuli. Psychophysiology, 15, 93-101.

Öhman, A., Fredrikson, M., Hugdahl, K., \& Rimmö, P.-A. (1976). The premise of equipotentiality in human classical conditioning: Conditioned electrodermal responses to potentially phobic stimuli. Journal of Experimental Psychology: General, 105, 313-337.

Overmier, J., Patterson, J., \& Wielkiewicz, R. (1980). Environmental contingencies as sources of stress in animals. In $S$. Levine \& $H$. Ursin (Eds.), Coping and health (pp. 1-38). New York: Plenum Press.

Plimpton, E., Swartz, K., \& Rosenblum, L. (1981). Responses of juvenile bonnet macaques to social stimuli presented through color videotapes. Developmental Psychobiology, 14, 109-115.

Rachman, S., \& Hodgson, R. (1974). Synchrony and desynchrony in fear and avoidance. Behaviour Research and Therapy, 12, 311318.

Rescorla, R., \& Wagner, A. (1972). A theory of Pavlovian conditioning: Variations in the effectiveness of reinforcement and nonreinforcement. In A. Black \& W. Prokasy (Eds.), Classical conditioning $I I$ (pp. 64-99). New York: Appleton-Century-Crofts.

Rogan, J., Keselman, H., \& Mendoza, J. (1979). Analysis of repeated measurements. British Joumal of Mathematical and Statistical Psychology, 32, 269-286.

Russell, P. (1979). Fear-evoking stimuli. In W. Sluckin (Ed.), Fear in animals and man (pp. 86-124). New York: Van Nostrand Reinhold.

Sackett, G. (1970). Unlearned responses, differential rearing experiences, and the development of social attachments by rhesus monkeys. In L. Rosenblum (Ed.), Primate behavior: Development in field and laboratory research (Vol. 1, pp. 112-140). San Diego, CA: Academic Press.

Sackett, G. (1978). Measurement in observational research. In G. Sackett (Ed.), Observing behavior: Vol. 2. Data collection and analysis methods (pp. 25-43). Baltimore: University Park Press.

Schaik, C. van, Noordwijk, M. van, Boer, R. de, \& Tonkelaar, I. den. (1983). The effect of group size on time budgets and social behaviour in wild long-tailed macaques (Macaca fascicularis). Behavioral Ecology and Sociobiology, 13, 173-181.

Seligman, M. (1970). On the generality of the laws of learning Psychological Review, 77, 406-418.

Seligman, M. (1971). Phobias and preparedness. Behavior Therapy, 2, 307-320.

Seyfarth, R., Cheney, D., \& Marler, P. (1980a). Monkey responses to three different alarm calls: Evidence of predator classification and semantic communication. Science, 210, 801-803.

Seyfarth, R., Cheney, D., \& Marler, P. (1980b). Vervet monkey alarm calls: Semantic communication in a free-ranging primate. Animal Behaviour, 28, 1070-1094.

Shapiro, K., Jacobs, W., \& LoLordo, V. (1980). Stimulus-reinforcer interactions in Pavlovian conditioning of pigeons: Implications for selective associations. Animal Learning and Behavior, 8, 586-594.

Shapiro, K, \& LoLordo, V. (1982). Constraints on Pavlovian conditioning of the pigeon: Relative conditioned reinforcing effects of red-light and tone CSs paired with food. Learning and Motivation, 13, 68-80.

Struhsaker, T. (1967). Auditory communication among vervet monkeys (Cercopithecus aethiops). In S. Altmann (Ed.), Social communication among primates (pp. 281-324). Chicago: University of Chicago Press.

Turner, C. (1968). Models of discrimination learning. Unpublished doctoral dissertation, Oxford University.

Vasey, M., \& Thayer, J. (1987). The continuing problem of false positives in repeated measures ANOVA in psychophysiology: A multivariate solution. Psychophysiology, 24, 479-486.

Venn, J., \& Short, J. (1973). Vicarious classical conditioning of emotional responses in nursery school children. Journal of Personality and Social Psychology, 28, 249-255.

Waddington, C. (1957). The strategy of the genes. London: George Allen Unwin.

Zeaman, D., \& House, B. (1962). Approach and avoidance in the discrimination learning of retardates. Child Development, 33, 355372.

Received August 17, 1989

Revision received April 20, 1990

Accepted April 30, 1990 